Article

\title{
Enhanced Senescence Process is the Major Factor Stopping Spike Differentiation of Wheat Mutant ptsd1
}

\author{
Zhixin Jiao ${ }^{1}$, Junchang $\mathrm{Li}^{1}{ }^{1}$, , Yongjing $\mathrm{Ni}^{2}$, Yumei Jiang ${ }^{1}$, Yulong Sun ${ }^{1}$, Junhang An ${ }^{1}$, \\ Huijuan $\mathrm{Li}^{1}{ }^{1}$, Jing Zhang ${ }^{1}$, Xin $\mathrm{Hu}^{2}$, Qiaoyun $\mathrm{Li}^{1}$ and Jishan Niu ${ }^{1, *}$ \\ 1 National Centre of Engineering and Technological Research for Wheat/Key Laboratory of Physiological \\ Ecology and Genetic Improvement of Food Crops in Henan Province, Henan Agricultural University, \\ Zhengzhou 450046, Henan, China; zxjiao2018@163.com (Z.J.); chang_top@163.com (J.L.); \\ nxyjym@henau.edu.cn (Y.J.); ylsun1994@163.com (Y.S.); jhan68@163.com (J.A.); 1hj19960901@163.com (H.L.); \\ jzhang1023@126.com (J.Z.); liqiaoyun@henau.edu.cn (Q.L.) \\ 2 Shangqiu Academy of Agricultural and Forestry Sciences, Shangqiu 476000, Henan, China; \\ nyj317@163.com (Y.N.); huxin2699552@163.com (X.H.) \\ * Correspondence: jsniu@henau.edu.cn; Tel.: +86-0371-5699-0186
}

Received: 15 August 2019; Accepted: 17 September 2019; Published: 19 September 2019

\begin{abstract}
Complete differentiation of the spikes guarantees the final wheat (Triticum aestivum L.) grain yield. A unique wheat mutant that prematurely terminated spike differentiation ( $p t s d 1$ ) was obtained from cultivar Guomai 301 treated with ethyl methane sulfonate (EMS). The molecular mechanism study on $p t s d 1$ showed that the senescence-associated genes (SAGs) were highly expressed, and spike differentiation related homeotic genes were depressed. Cytokinin signal transduction was weakened and ethylene signal transduction was enhanced. The enhanced expression of $\mathrm{Ca}^{2+}$ signal transduction related genes and the accumulation of reactive oxygen species (ROS) caused the upper spikelet cell death. Many genes in the WRKY, NAC and ethylene response factor (ERF) transcription factor (TF) families were highly expressed. Senescence related metabolisms, including macromolecule degradation, nutrient recycling, as well as anthocyanin and lignin biosynthesis, were activated. A conserved tae-miR164 and a novel-miR49 and their target genes were extensively involved in the senescence related biological processes in $p t s d 1$. Overall, the abnormal phytohormone homeostasis, enhanced $\mathrm{Ca}^{2+}$ signaling and activated senescence related metabolisms led to the spikelet primordia absent their typical meristem characteristics, and ultimately resulted in the phenotype of ptsd1.
\end{abstract}

Keywords: wheat (Triticum aestivum L.); mutant ptsd1; spike differentiation; senescence-associated genes $(S A G s) ;$ homeotic gene; phytohormone; $\mathrm{Ca}^{2+}$ signaling

\section{Introduction}

Wheat spike differentiation is a key developmental stage as a transition from vegetative growth to reproductive growth in wheat (Triticum aestivum L.) [1]. Complete differentiation of the spikes guarantees the final wheat grain yield [2]. In general, the indeterminate inflorescence meristem of wheat can initiate conversion into spikelet meristem, followed by the initiation of glume primordia, lemma primordia and ultimately form a unique reproductive inflorescence unit termed a spikelet [1]. The wheat spike mutants are ideal germplasm resources for molecular genetic studies on wheat spike development. Up to now, only one "degenerated spike" mutant is obtained from EMS treated winter wheat Jing411 [3]. The upper spikelets develop slowly and cease growth completely after heading, however, the molecular mechanisms remain unknown. Understanding the molecular mechanisms of spike degeneration will be valuable for improving wheat yield potential. 
The ABCDE model for plant flower development proposes that floral organ identity is defined by five classes of homeotic genes, named A, B, C, D, and E [4]. Generally, the ABCDE model is equally fit for monocots like rice and wheat $[5,6]$. According to this model, the class A genes determine lemma and palea identity, the class B genes specify lodicule and stamen identity, the class C and D genes specify stamen and ovule identity, and the class $\mathrm{E}$ genes specify organ identity and determine the spikelet meristem [6,7]. Wheat TaFL (FLORICAULA/LEAFY ortholog) is associated with spikelet formation [8]. Wheat Flowering locus T2 (TaFT2) is expressed in the distal part of the developing spikes and contributes to the regulation of the number of spikelets per spike [9]. The miRNA172- $Q$ gene (AP2 like gene) system plays a crucial role in spike morphogenesis [10]. Overexpression of miRNA172 leads to elongated spikes [11]. Although a few genes related to spike differentiation have been reported in wheat, the gene regulatory network remains largely unknown.

Plant hormones are key regulators of spikelet differentiation and degeneration [12]. In rice, the auxin signaling is related to the phenotype of premature termination of spikelet development in aberrant spikelets and panicle1 (asp1) mutant [13]. Cytokinins (CKs) can enhance plant growth and promote floret development [12]. In contrast to auxin and CKs, ethylene (ET) is generally regarded as an inhibitory growth regulator [14]. ET plays a vital role in floret degeneration and spikelet degeneration in the plant $[15,16]$. However, the molecular mechanism of the cross-talk among hormones in suppressing or enhancing spikelet degeneration remains unknown.

Senescence affects vegetative and productive developmental processes in plants, several SAGs have been discovered in model plant Arabidopsis thaliana [17]. During wheat senescence processes, proteins are degraded, and nutrients are re-mobilized from senescing leaves to other organs [18]. Many genes involved in metabolism, degradation and regulator processes have been identified from a wheat premature leaf senescence mutant $m 68$ [19]. A number of leaf senescence regulatory genes are identified, notably NAC-domain and WRKY genes [20,21]. A NAC gene (Gpc-B1) is isolated from wild emmer wheat (Triticum turgidum ssp. dicoccoides), and it can accelerate senescence and increase nutrient remobilization from leaves to developing grains [22]. There are some reports about wheat senescence of vegetative organs, however, little is known about that of productive organs $[18,19,23]$. Some miRNAs participate in regulating leaf senescence such as miR164. The feed-forward signaling cascade involving ETHYLENE-INSENSITIVE2 (EIN2), EIN3, miR164, and ORE1 plays an important role in the processes of leaf senescence in Arabidopsis [24,25].

Previously, we have obtained several stable hereditary prematurely terminated spike differentiation (ptsd) mutants from the EMS treated wheat cultivar "Guomai 301" and "Shengnong 1" [26,27]. Among them $p t s d 1$ is one of the carefully researched mutants. Most plants of $p t s d 1$ only grow several grains, while the extreme individuals grow no grains completely. Genetic analysis indicates that it's regulated by recessive genes. Up to now, we haven't found such kind of mutants have been reported in wheat. It provides an opportunity for us to explore how wheat regulates its spike differentiation. To analyze the molecular network regulating the abnormal spike differentiation of mutant $p t s d 1$, we compared the transcriptomes and miRNomes of the wide type (WT) and mutant $p t s d 1$ at the early spike differentiation stage. Our results suggested that $S A G s$ were highly expressed, programmed cell death (PCD) was enhanced, ethylene signal transduction related genes and the degradation related genes of cytokinins were highly expressed in ptsd1. Global analysis of the metabolism related differentially expressed genes (DEGs) and measurement of the metabolism indicators revealed that the degradation of macromolecules and the biosynthesis pathway of phenylpropanoids were enhanced in mutant $p t s d 1$.

\section{Results}

\subsection{The Upper Spikelets of the Mutant ptsd1 Didn't Differentiate}

The agronomic traits of $p t s d 1$ and its wild type parent (WT) were compared, especially their spikes were carefully observed during differentiation and development. The average spike length, fertile spikelet number and seed number per spike of the ptsd 1 were only $4.19 \mathrm{~cm}, 4.50 \mathrm{~cm}$ and $14.16 \mathrm{~cm}$ 
respectively, they decreased by $60.0 \%, 77.5 \%$ and $80.0 \%$ compared to those of the WT (Figure 1A,B, Table S1).

In WT, each spike had 19-21 fertile spikelets (average number was 20) (Table S1), each spikelet primordium differentiated into a spikelet comprising 3-5 florets. The first visible differentiated structures were glume primordium and lemma primordium, and then one floret primordium, the three stamen primordia and the pistil primordium in each floret can be seen as independent structures at the terminal spikelet stage (Figure 1C). In ptsd1, each spike only had 3-6 fertile spikelets (average number was 4.5) (Table S1). The differentiation of the upper spikelets terminated prematurely at about late double ridge stage (Figure S1I), the spikelet primordia only formed some small bumps in the end (Figure 1D), however, the under spikelets differentiated almost normally (Figure 1D). The date of apex differentiation (transition period) of ptsd1 was about one week later than that of WT, and the dates of heading, anthesis, and maturity were about ten days later than those of the WT (Table S1).
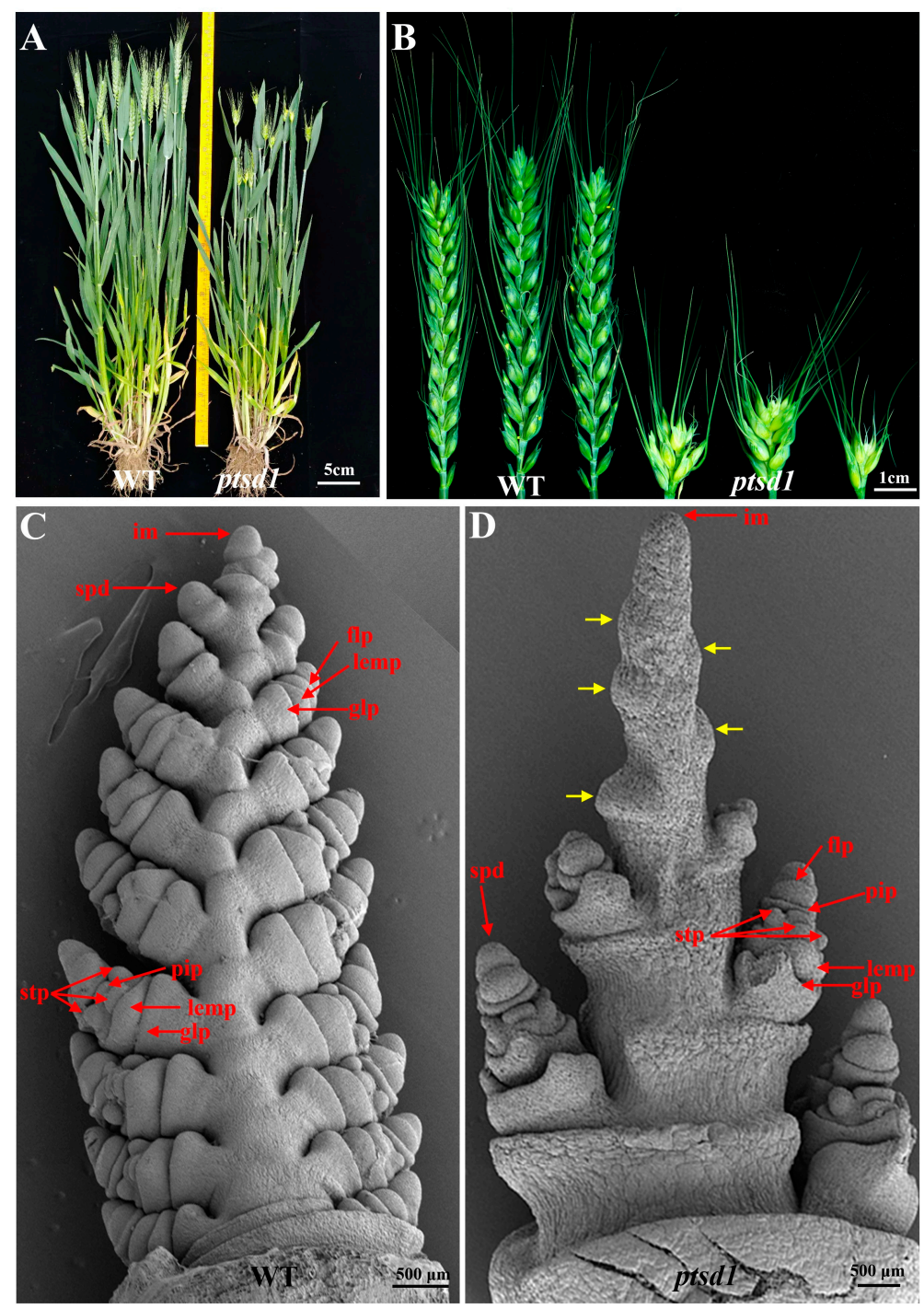

Figure 1. The individual plants and spikes of wild type (WT) and mutant ptsd1. (A) The plant phenotype of WT (left) and mutant ptsd1 (right); (B) The spikes of WT (left) and mutant ptsd1 (right); (C) The ultrastructure of the young spikes on WT at terminal spikelet stage; (D) The ultrastructure of the young spikes on mutant ptsd1 at late terminal spikelet stage. Yellow arrowheads indicate the undifferentiated upper spikelet primordia. im, inflorescence meristem; spd, spikelet meristematic dome; glp, glume primordium; lemp, lemma primordium; flp, floret primordium; stp, stamen primordium; pip, pistil primordium. 


\subsection{The Meristem Characteristics of the Undifferentiated Spikelet Primordia on the ptsd1 Were Absent}

The enlargement of spikelet primordia proceeded in both acropetal and basipetal orientations during spike morphogenesis at late double ridge stage [28] in WT (Figure S1C). The spikelet primordia possessed typical meristem characteristics, such as small cells, none or very small vacuoles, dense cytoplasm, relatively bigger nuclei and thinner cell wall (Figure S2A). However, the upper spikelet primordia of $p t s d 1$ didn't differentiate, and the bottom spikelet primordia initiated differentiation at this stage (Figure S2C). At the initiation of the second awn stage, the stamen and pistil primordia could be seen in both WT and the bottom spikelets of $p t s d 1$ (Figure S2B), however, the upper spikelet primordia of $p t s d 1$ were still at about the double ridge stage without typical meristem (Figure S2D).

\subsection{Gene Transcripts Were Abundant in ptsd1}

To eliminate the interference of genes involved in stem development and identify spike differentiation specific genes, the "stem tips" below young spikes were used as control samples. A total of $131.73 \mathrm{G}$ data were obtained from the four super bulked samples at late double ridge stage: young stem tips of WT (WT-ST; T1a, T1b, T1c), young spikes of WT (WT-YS; T2a, T2b, T2c), young stem tips of $p t s d 1$ (ptsd1-ST; T3a, T3b, T3c) and young spikes of $p t s d 1$ (ptsd1-YS; T4a, T4b, T4c). The mapping rates of the reads in each library to reference wheat genome ranged from $79.23 \%$ to $82.46 \%$ (Table S2). The Pearson's correlation coefficients among the three replicates for each sample ranged from 0.9323 to 0.9946 (Table S3), indicating that the three biological replicates were consistent. The principal components analysis indicated that the three biological replicates were clustered together in one ellipse (Figure S3A).

A total of 4439 genes were significantly differentially expressed between $p t s d 1-Y S$ and WT-YS. Among them 3532 DEGs were highly, only 907 DEGs were lowly expressed in $p t s d 1-Y S$ (Figure S3B) (A/B, Up: the expression level in A was higher than B, and down: the opposite.). Obviously, the expressions of most DEGs in differentiating spikes of $p t s d 1$ were higher.

\subsection{Senescence Related Biological Process in Mutant ptsd1}

A total of 4871 genes were significantly differentially expressed among WT-YS/WT-ST, ptsd1-ST/WT-ST, ptsd1-YS/WT-YS and ptsd1-YS/ptsd1-ST (Table S4). All the DEGs were clustered by $k$-means setting the $k$ as seven (Table S5). These clusters displayed various gene expression patterns which were correlated with their functions. The abnormal expression patterns of the DEGs led to the prematurely terminated spike differentiation in $p t s d 1$.

There were 364 and 204 DEGs in clusters 1 and 5, and they were most highly expressed in WT-YS and lowly expressed in ptsd1-YS (Figure 2A). Enrichment analysis of these genes in clusters 1 and 5 revealed that most of them were involved in spike differentiation related biological processes such as the top three GO terms of "flower development, meristem development", and "cell differentiation" (Figure 2C). This indicated that the spike differentiation related genes were lowly expressed in ptsd1-YS. Contrarily, 340 and 2004 genes in clusters 2 and 7 were most highly expressed in $p t s d 1-Y S$ (Figure 2A). Enrichment analysis indicated that most of them were involved in senescence related biological processes such as the top five GO terms of "cell wall macromolecule catabolic process" which involved in cell wall macromolecule degradation, "glutathione transferase activity" involved in detoxification, "chitin binding" involved in chitin degradation, "systemic acquired resistance, salicylic acid mediated signaling pathway" involved in PCD and the "negative regulation of PCD" involved in cell senescence (Figure 2C). This indicated that senescence related genes were highly expressed in ptsd1-YS. The qRT-PCR analyses showed that the expression patterns of eight representative genes in classes 1, 2 and 7 were well consistent with that of the sequencing results (Figure 2B). The spike differentiation related genes (TaSEP5, TaSEP6 and TaFL) in cluster 1 were lowly expressed in ptsd1-YS, the senescence related genes (TaCht, TaGSTF2 and TaGS1a) in cluster 7 were highly expressed in ptsd1-YS. 

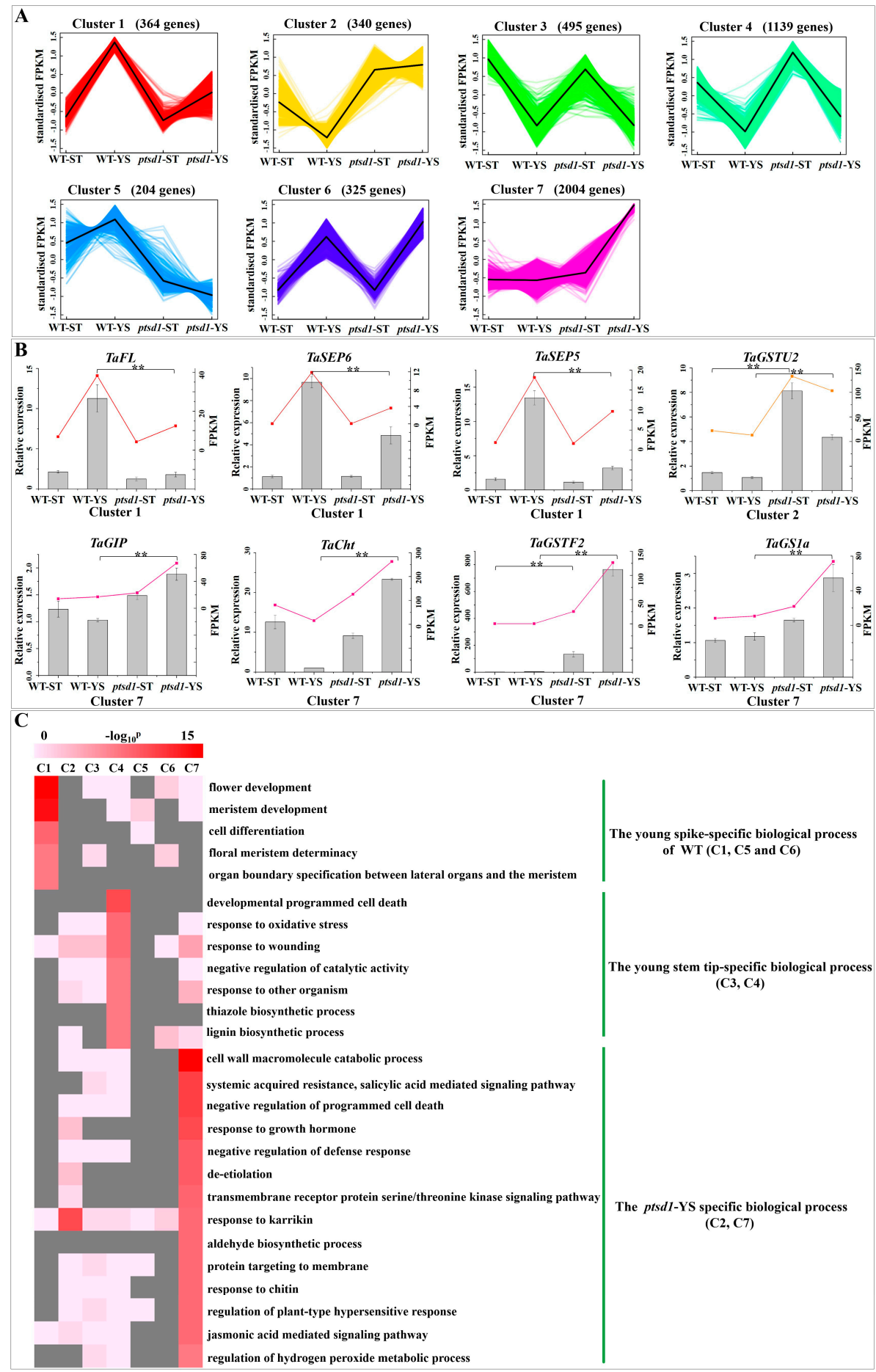

Figure 2. The expression profiles and functional enrichment of the differentially expressed genes (DEGs). (A) $\mathrm{K}$-means clusters of the DEGs. The $\mathrm{X}$-axis indicates the samples, $\mathrm{Y}$-axis indicates the normalized fold-changes of the gene expression levels. (B) The expression patterns of some key genes verified by real-time qRT-PCR. The X-axis indicates samples. The left $\mathrm{Y}$-axis indicates relative gene expression levels determined by qRT-PCR and the expression values were adjusted by setting the minimum expression as 1 for each gene. The right Y-axis indicates the fragments per kilobase of transcript per million fragments mapped (FPKM). The asterisk indicates the significant difference between different samples (**: $p \leq 0.01)$. (C) GO-term function enrichment of different clusters. The significances of the most represented GO-slims in each main cluster are indicated using log-transformed $p$-value (red). The dark grey areas represent the missing values. C1-C7: cluster1-cluster7. 


\subsection{Functional Categorization of the DEGs Between ptsd1-YS and WT-YS}

The genes were considered as not expressed if their average fragments per kilobase of transcript per million fragments mapped (FPKM) $<1$ in samples. Ultimately, 2582 DEGs had at least fourfold change in transcript abundance between ptsd1-YS and WT-YS were identified (Table S6), and they were sorted into 10 putative functional groups according to their annotation (Figure 3). The unclassified (325) and unknown function (659) DEGs took up 38\% of the total DEGs (Table S7). The other functional categories of the genes in the central pie chart comprised regulation (25.3\%), protein and amino acid metabolism $(9.8 \%)$, stress/defence $(6.4 \%)$, transport $(6.0 \%)$, secondary metabolism $(6.2 \%)$, lipid metabolism $(3.9 \%)$, carbohydrate metabolism (3.6\%) and nucleotide metabolism (0.7\%) (Table S7). The genes encoding putative regulatory proteins in the left pie chart and the genes involved in macromolecule degradation of four major nutrients in the right pie chart are discussed in detail in the following sections (Figure 3).

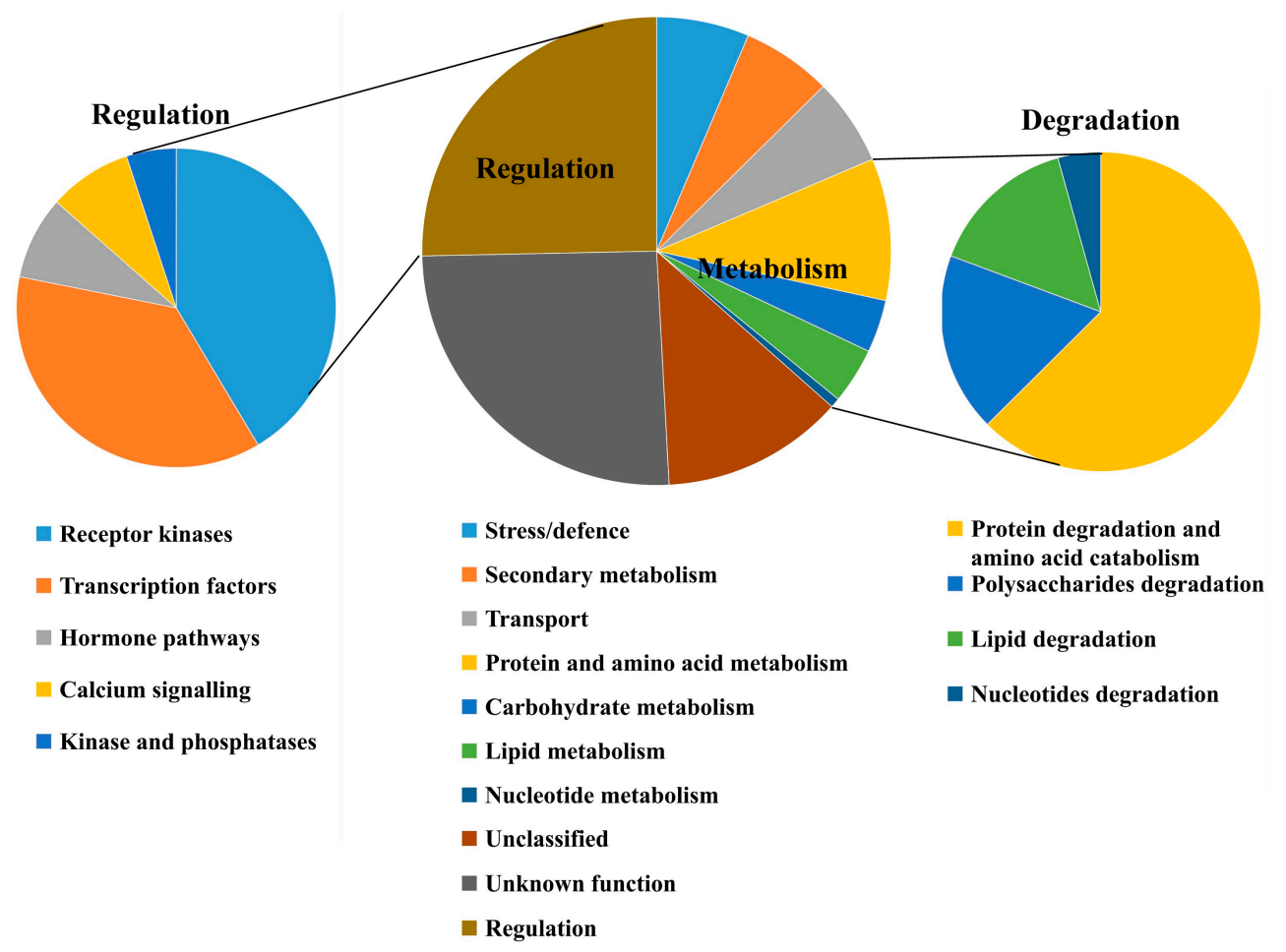

Figure 3. Potential functions of the DEGs between $p t s d 1-Y S$ and WT-YS. The groups are illustrated by the central pie chart with extra charts. Left chart indicates the genes encoding putative regulatory proteins. Right chart indicates the genes involved in macromolecule degradation of four major nutrients. The gene annotation information is listed in Table S7.

\subsection{Hormone and TF-Related Genes Were Highly Expressed in ptsd1}

A total of 132 DEGs (FC $\geq 2$ ) were associated with various aspects of hormone homeostasis, such as biosynthesis, response, signaling and metabolism (Table S8). The top two groups of the significant DEGs were related to ET and CK (Figure S4A,B). Among ET signal transduction-related genes, twelve homologs of ethylene insensitive (EIN) genes were highly expressed in $p t s d 1$. Meanwhile, several ET signal-related genes were highly expressed in $p t s d 1$, including the homologs of ethylene response factor (Figure S4A). The enhanced expression of ET-biosynthesis and signal transduction related genes in ptsd1 suggested that more active ET signaling might be a major factor leading to the phenotype of ptsd1. A total of $25 \mathrm{CK}$ metabolism and response genes were differentially expressed between $p t s d 1-\mathrm{YS}$ and WT-YS (Figure S4B). Among them, the expressions of the CK-degrading and CK-inactivating related homologs were highly expressed in $p t s d 1$ (Figure S4B). Owing to the fact that CK-degrading and CK-inactivating related genes were highly expressed, the CK concentration in $p t s d 1$ was lower (Figure S4C). 
We identified 240 putative TF DEGs between $p t s d 1-Y S$ and WT-YS. They belonged to 31 TF families (Table S9). The WRKY (42) and NAC (32) families were the top two largest families having the most DEGs (Figure S5), and most of them were highly expressed in $p t s d 1-Y S$.

\subsection{The Expression of Many Homeotic Genes Were Depressed in ptsd1}

We isolated 28 differentially expressed MADS-box TFs from the four samples. The expressions of most MADS-box genes were reduced in $p t s d 1$, such as the homologs of class E gene sepallata/agamous-like gene 2 (SEP/AGL2), the class B genes pistillata (PI) and apetala 3 (AP3) (Figure S6, Tables $\mathrm{S} 10$ and S11). The E-class MADS-box genes TaSEP5 and TaSEP6, which specify organ identity and determine the spikelet meristem, were lowly expressed in $p t s d 1-Y S$ during the young spike differentiation stages (Figure 4). The homeotic gene TaFL, which is associated with spikelet formation, was also lowly expressed in $p t s d 1$-YS (Figure 4). Obviously, the expression of many homeotic genes was depressed in $p t s d 1$.

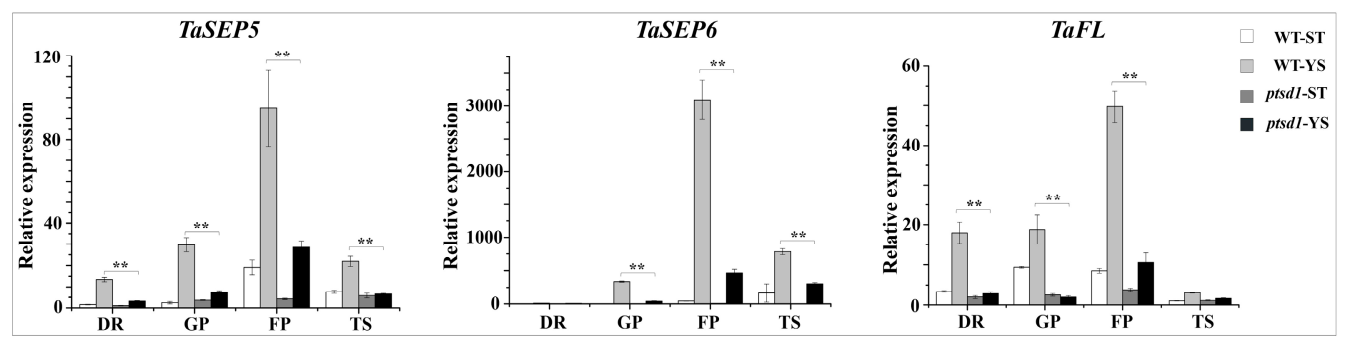

Figure 4. Expression patterns of three homeotic genes. Double ridge stage (DR), glume primordium visible stage (GP), floret primordium visible stage (FP) and terminal spikelet stage (TS). The asterisk indicates the significant difference between different samples $\left({ }^{* *}: p \leq 0.01\right)$.

\subsection{DEGs Involved in Protein Modification and Calcium Signaling Were Highly Expressed in ptsd1-YS}

Many DEGs involved in protein modification, such as receptor-like kinases, protein kinases, and phosphatases, were highly expressed in ptsd1-YS (Tables S12 and S13). Among the 307 protein modification related DEGs belonging to 40 subfamilies, 289 were highly expressed, and only 19 were lowly expressed in $p t s d 1$. The receptor-like kinase (RLK/Pelle), legume lectin (L-LEC) subfamily (41) and DUF26-Ib subfamily (39) were the top three largest families having the most DEGs between ptsd1-YS and WT-YS (Figure S7). A total of 50 DEGs were related to $\mathrm{Ca}^{2+}$ signaling (Table S12). Most $\mathrm{Ca}^{2+}$ signaling DEGs were highly expressed in $p t s d 1$.

\section{9. $\mathrm{Ca}^{2+}$ Influx and ROS Accumulation Caused Hypersensitive Response (HR)-Related PCD in ptsd1}

The concentration of $\mathrm{H}_{2} \mathrm{O}_{2}$ in ptsd1-YS was significantly increased by $31 \%$ compared to WT-YS (Figure 5A). ROS is usually associated with plant defense response and HR. In our study, totally 140 DEGs, 131 highly and 9 lowly expressed in ptsd1-YS, were involved in ROS signaling (Table S14), including genes encoding LRR receptor-like serine/threonine-protein kinase (FLS2), WRKY, mitogen-activated protein kinase (MAPK), cyclic nucleotide-gated ion channel (CNGCs), calcium-binding protein (CaMCML), calcium-dependent protein kinase (CDPK), respiratory burst oxidase homolog protein (Rboh), disease resistance protein (RPS2 and RPM1) and heat shock protein 90 (HSP90) (Figure S8A,B). We proposed that the accumulation of cytosolic $\mathrm{Ca}^{2+}$, the activation of MAPKs, the ROS, and the expression of defense related WRKY TFs were involved in HR-related PCD, which was caused by oxidative damage in $p t s d 1$. The ROS accumulation caused oxidative damage and cell death, which was consistent with the result of TUNEL assay that DNA degradation was widespread in the undifferentiated upper spikelets of the ptsd1 (Figure 5G). 


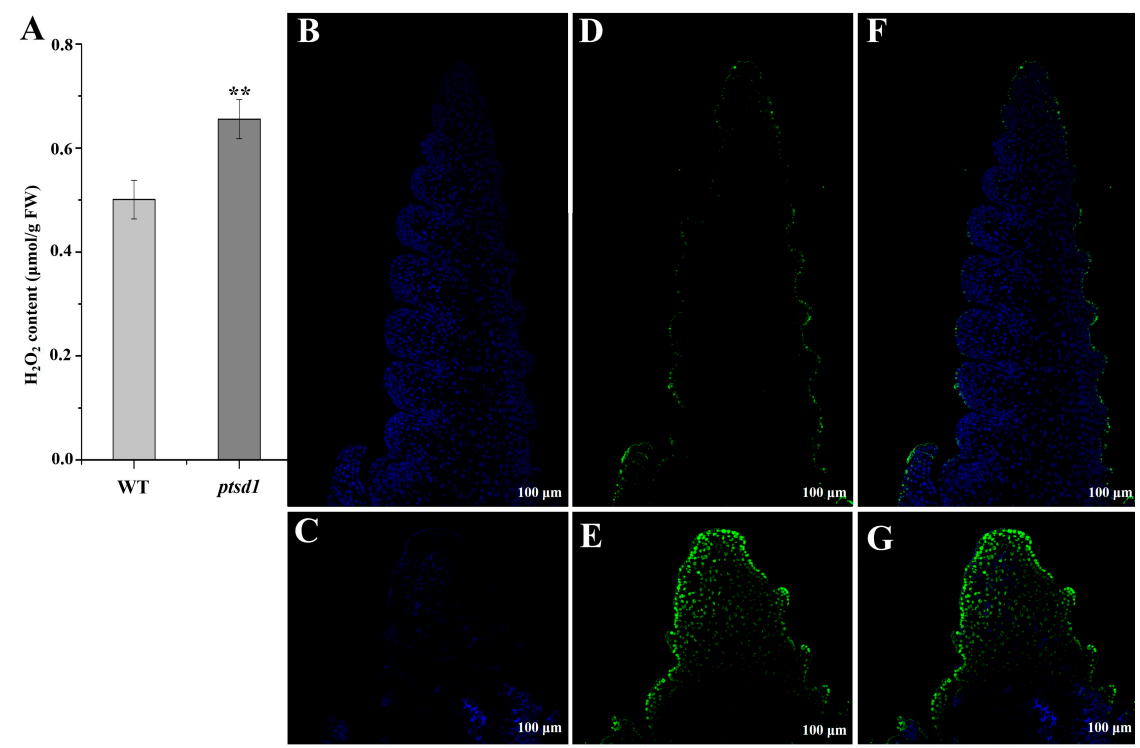

Figure 5. The $\mathrm{H}_{2} \mathrm{O}_{2}$ contents (A) and TUNEL assay (B-G) of WT and ptsd1. (A) The $\mathrm{H}_{2} \mathrm{O}_{2}$ contents in young spikes of WT and $p t s d 1$. The asterisks represent the significant difference between $\mathrm{WT}$ and $p t s d 1$ $\left(^{* *}: p \leq 0.01\right)$. FW, fresh weight. (B-G) TUNEL assay results of WT and $p t s d 1$. The young spikes were at late double ridge stage. The spikes of WT (B) and $p t s d 1$ (C) stained with DAPI. Positive stained results of WT (D) and ptsd1 (E) with fluorescein. (F) is the overlap picture of $(\mathbf{B}, \mathbf{D}) ;(\mathbf{G})$ is the overlap picture of $(\mathbf{C}, \mathbf{E})$. Green indicates the programmed cell death (PCD).

\subsection{Degradation of Macromolecules in ptsd1}

A distinct feature of $p t s d 1$ was the active massive degradation of macromolecules, such as proteins, polysaccharides, lipids, and nucleotides, as well as the biosynthesis of secondary metabolites. This was evidenced by the fact that, among the highly expressed genes of protein and amino acid, polysaccharide, lipid, nucleotide, and secondary metabolism in ptsd1, the ratios of the catabolism-related genes to anabolism-related genes were 12.75, 3.15, 1.14, 7.00 and 0.07 respectively (Tables S15 and S16). A total of 74 genes involved in potential ubiquitin-proteosome proteolytic pathways were highly expressed in $p t s d 1$ and this indicated that protein degradation via the $26 \mathrm{~S}$ proteosome was active during the upper spikelet degradation processes in ptsd1 (Figure S9A, Tables S17 and S18). In addition to ubiquitin-proteosome proteolytic pathways, 25 genes encoding the proteinases were highly expressed in $p t s d 1$ (Table S17, Figure S9A). In ptsd1-YS, the contents of proteins were significantly decreased by $25.0 \%$. (Figure $6 \mathrm{~A}$ ). The content of protein was lower in undifferentiated upper spikelets of $p t s d 1$ compared to the spikes of WT by histochemical observation (Figure S10). The content of total sugar was significantly decreased by $5.7 \%$ in $p t s d 1$ (Figure 6B). The chitinase encoding gene TaCht, which involved in degradation of chitin polysaccharide, was highly expressed in ptsd1 (Figure 7A). The chitinase activity was 1.4-fold higher in $p t s d 1$ than that in WT (Figure 7B). 
A
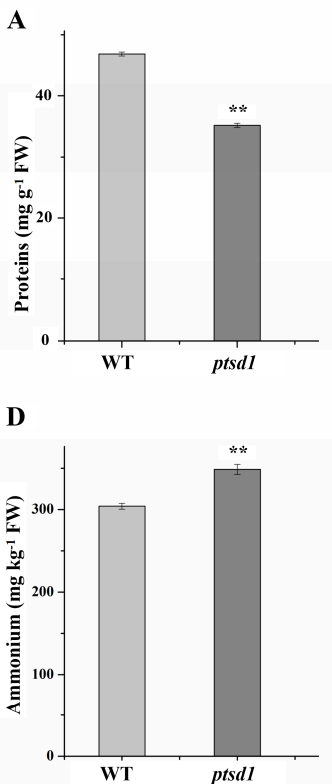

B

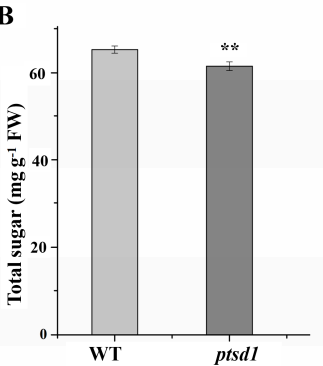

$\mathbf{E}$

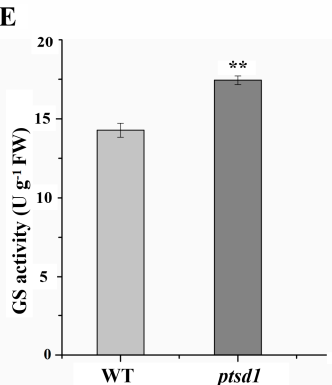

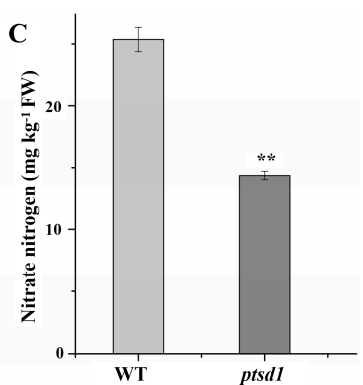

F

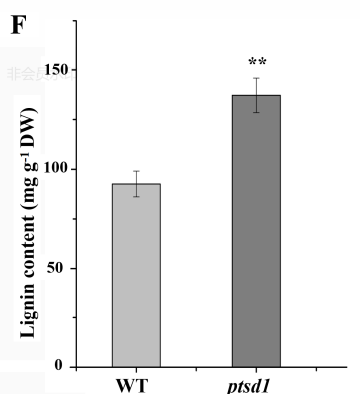

Figure 6. Physiological traits of WT and ptsd1. The contents of proteins (A), total sugar (B), nitrate nitrogen (C), ammonium nitrogen (D), GS activity (E) and lignin (F) in spikes of WT and ptsd1. Each sample has three independent biological replicates. Bars indicate the standard deviation. FW, fresh weight; DW, dry weight. The asterisks represent the significant difference between WT and ptsd1 $(* *: p \leq 0.01)$.

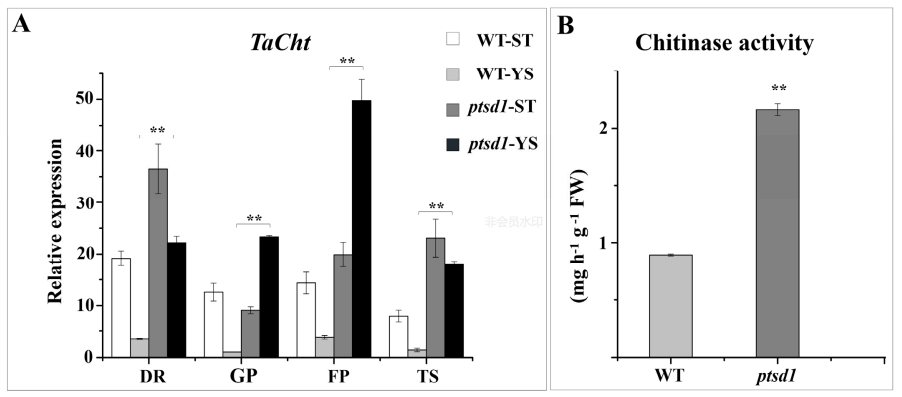

Figure 7. Expression pattern of chitinase gene TaCht and chitinase activity in spikes of WT and ptsd1. The asterisks represent the significant difference between WT and $\left.p t s d 1{ }^{* *}: p \leq 0.01\right)$.

\subsection{N recycling, Anthocyanin and Lignin Biosynthesis in ptsd1}

In $p t s d 1$, phenylalanine ammonia-lyase, guanine deaminase and fatty acid amide hydrolase encoding genes were highly expressed. $\mathrm{N}$ was released primarily from protein degradation, nucleic acid catabolism and amide hydrolysis (Figure S9C, Figure 8A). The released $\mathrm{N}$ is assimilated, generally in the form of $\mathrm{NH}_{4}{ }^{+}$, via the glutamate decarboxylase and GS-catalyzed synthesis reaction and eventually produced glutamine (Figure $8 \mathrm{~A}$ ).

Metabolic indicators were measured to verify the hypothetical model of $\mathrm{N}$ recycling and anthocyanin and lignin biosynthesis gene regulatory network proposed according to the RNA-seq data in Figure 8. In $p t s d 1$, the content of nitriate nitrogen was significantly decreased by $43.3 \%$, while the content of $\mathrm{NH}_{4}{ }^{+}$was significantly increased by $14.7 \%$ (Figure $6 \mathrm{C}, \mathrm{D}$ ). TaGS1a was highly expressed (Figure 2B), and the GS activity was significantly increased by $22.2 \%$ (Figure 6E). A total of seven ammonium transporter encoding genes, which participated in ammonium transport, were highly expressed in ptsd1 (Figure 8A). Assimilation of $\mathrm{NH}_{4}{ }^{+}$in plant cells is catalyzed by GS, which is important for nitrogen assimilation and recycling. Meanwhile, the content of lignin was significantly increased by $48.2 \%$ in $p t s d 1$ (Figure $6 \mathrm{~F}$ ), which was in agreement with the highly expressed lignin biosynthesis related genes (Figure $8 \mathrm{~B}$ ). Above all, the macromolecules, especially proteins, were degraded in $p t s d 1$, 
the $\mathrm{N}$ was recycled in the form of $\mathrm{NH}_{4}{ }^{+}$, and the anthocyanin and lignin biosyntheses were enhanced in $p t s d 1$ (Figure 8).

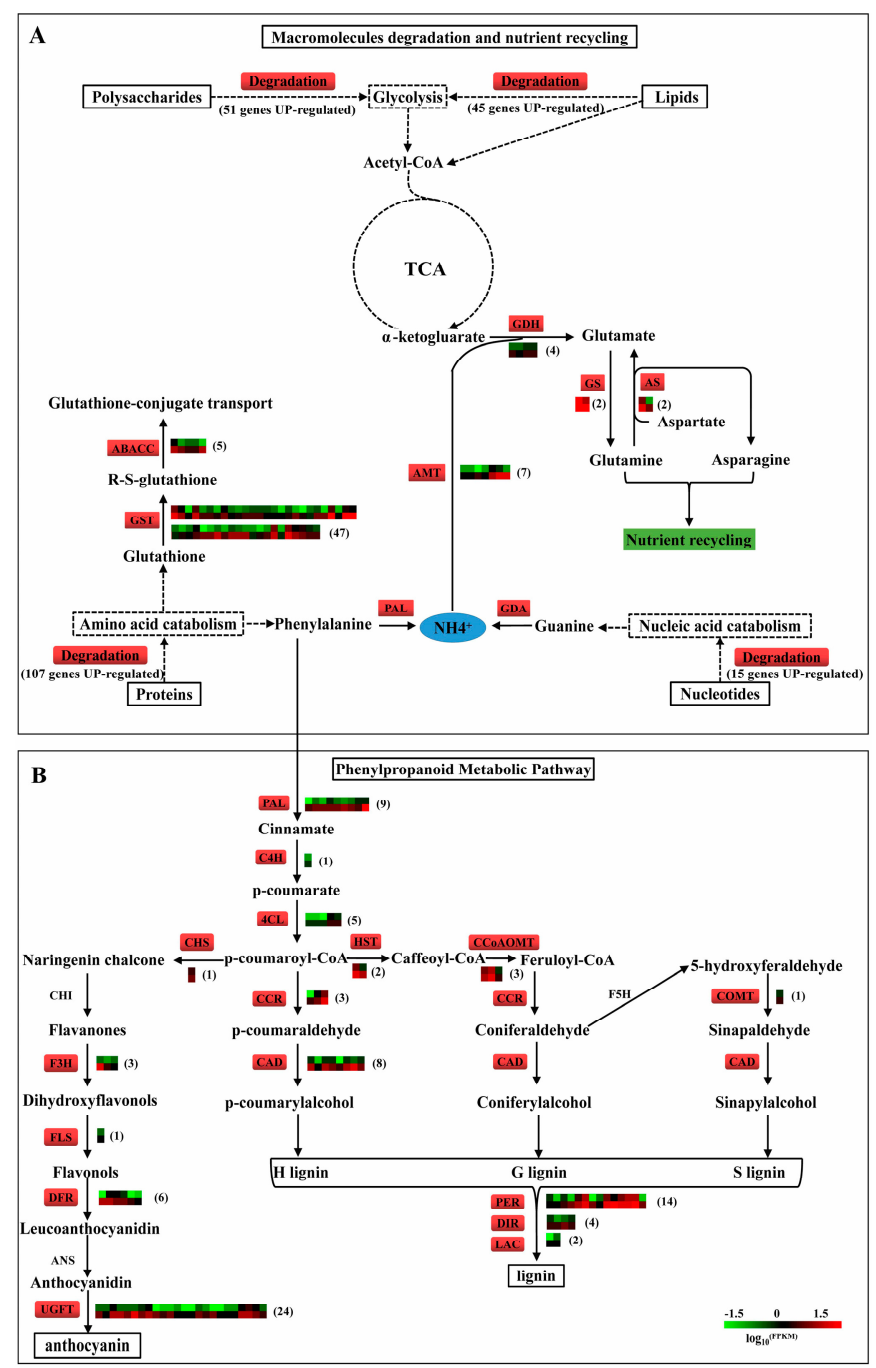

Figure 8. The key metabolic pathway and regulatory network in mutant ptsd1. (A) Macromolecule degradation and nutrient recycling in mutant ptsd1. (B) Overview of putative phenylpropanoid metabolic pathway involved in anthocyanin and lignin biosynthesis in ptsd1. TCA, tricarboxylic acid cycle; the box includes the critical enzymes comprising the entry pathway. Enzymes coloured in red indicate the highly expressed genes in ptsd1-YS, the heatmaps show the expression profiles between WT-YS (upside) and ptsd1-YS (downside), the figures in the parentheses are the numbers of DEGs. The real lines indicate the direct products, the dotted lines indicate the indirect products and metabolic process. $\mathrm{ABCC}$, $\mathrm{ABC}$ transporter C; GST, glutathione S-transferase; AMT, ammonium transporter; GDA, guanine deaminase; GDH, glutamate decarboxylase; GS, glutamine synthetase; AS, asparagine synthetase; PAL, phenylalanine ammonia-lyase; $\mathrm{C} 4 \mathrm{H}$, cinnamate 4-monooxygenase; $4 \mathrm{CL}$, 4-coumarate-CoA ligase; $\mathrm{CHS}$, chalcone synthase; $\mathrm{CHI}$, chalcone isomerase; F3H, naringenin, 2-oxoglutarate 3-dioxygenase; FLS, flavonol synthase; DFR, dihydroflavonol-4-reductase; ANS, anthocyanidin synthase; UFGT, anthocyanidin 5,3-O-glucosyltransferase; HST, shikimate O-hydroxycinnamoyl- transferase; CCR, cinnamoyl CoA reductase; $\mathrm{CAD}$, cinnamyl alcohol dehydrogenase; CCoAOMT, caffeoyl-CoAO-methyltransferase; COMT, tricetin 3,4,5apos-O- trimethyltransferase; PER, peroxidase; DIR, dirigent protein; LAC, laccase. The detailed information of the DEGs is listed in Tables S19 and S20. 
The GST encoding genes were significantly highly expressed in $p t s d 1$ compared to WT (Figure S11, Figure 8A). The expression levels of TaGSTF2 and TaGSTU2 evaluated by qRT-PCR and RNA-seq were highly consistent (Figure 2B). TaGSTF2 and TaGSTU2 were highly expressed in $p t s d 1$ during the young spike differentiation stage from late double ridge stage to terminal spikelet stage (Figure 9A). The GST activity was 15.5-fold higher in ptsd1-YS compared to WT-YS at late double ridge stage, meanwhile, the GST activity in root, leaf and stem of $p t s d 1$ was also significantly high (Figure 9B). The glutathione-conjugate transporter genes, which might participate in the transport of glutathione-conjugate products, were highly expressed in $p t s d 1$ (Figure S11).

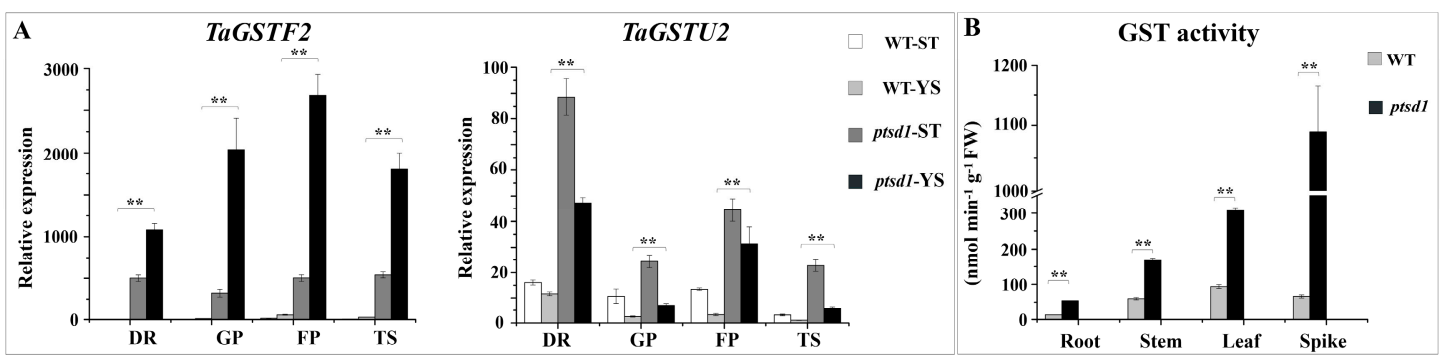

Figure 9. Expression patterns of GST encoding genes and GST activity in WT and ptsd1. The asterisk indicates the significant difference between different samples $\left({ }^{* *}: p \leq 0.01\right)$.

\subsection{Co-Expression Clusters of the DE miRNAs}

A total of 88 DE miRNAs were identified by the pairwise analysis (Table S21) in the twelve samples (WT-st: S1a, S1b, S1c; WT-ys: S2a, S2b, S2c; ptsd1-st: S3a, S3b, S3c; ptsd1-ys: S4a, S4b, S4c, the samples WT-st, WT-ys, ptsd1-st and ptsd1-ys were prepared from the same original samples of WT-ST, WT-YS, $p t s d 1-S T$ and $p t s d 1-Y S$, respectively). The clean read number of each sample was more than $15.32 \mathrm{M}$, the average Q30 percentage was more than $98.42 \%$ (Table S22).

The 88 DE miRNAs (Table S23) were classified into four groups using $k$-means cluster. 23 miRNAs in cluster 1 were most highly expressed in $p t s d 1,24$ miRNAs in cluster 2 were most lowly expressed in $p t s d 1$, twelve miRNAs in cluster 3 were most highly expressed in the young spikes and 29 miRNAs in cluster 4 were most highly expressed in the young stem tips (Figure S12A). The miRNAs in cluster 1 and 2 were the key regulators causing to the phenotype of $p t s d 1$. The qRT-PCR assay demonstrated that the expression patterns of the four representative miRNAs, novel-miR4, tae-miR159a, tae-miR167a and tae-miR9670-3p, were well consistent with that of the sequencing results (Figure S12B).

\subsection{DE miRNAs and Their Targets Involved in Senescence Related Biological Process in Mutant ptsd1}

The transcriptome analysis indicated that senescence related biological processes were related to ptsd1, including senescence related signal response and senescence related metabolism response. Further analysis identified 22 key miRNAs associated with the senescence related biological processes (Figure S13). There were nine miRNA targets were involved in the hormone and $\mathrm{Ca}^{2+}$ signaling activation (Figure S13), ten receptor-like kinases in RLK/Pelle family and nine TFs were involved in the signal transduction and transcriptional regulation of senescence related metabolisms (Figure S13). Seventeen miRNA targets were involved in senescence related metabolisms (Figure S13). The tae-miR164 and novel-miR49 were extensively involved in senescence related biological processes, and they had nine and fourteen targets respectively (Figure S13, Table S24). The novel-miR49 was lowly expressed in $p t s d 1$ compared to WT (Table S21).

\section{Discussion}

\subsection{The Undifferentiated Upper Spikelets of The Mutant Ptsd1 is A Kind of Senescence}

At the cellular level, senescence can be classified into two categories, mitotic senescence and postmitotic senescence [29]. An example of mitotic senescence in plants is the arrest of shoot apical 
meristem, which is also called proliferative senescence [30]. In Arabidopsis, the arrest development of floral buds is related to an irreversible cessation of cell expansion and differentiation, as well as cell division [31]. Similarly, the upper spikelet primordia of $p t s d 1$ stopped differentiation at about the late double ridge stage, and the tissues absented the typical meristem characteristics, cells terminated division, differentiation, and expansion soon after (Figure S1I-L). In this case, $p t s d 1$ should demonstrate a kind of mitotic senescence.

During wheat leaf senescence processes, proteins are degraded [32]. $\mathrm{H}_{2} \mathrm{O}_{2}$ plays an important role during the senescence process, and it could also be considered as a senescence signal and enhancer in different plant species, and it acts as an element of a complex regulatory network [33]. $\mathrm{H}_{2} \mathrm{O}_{2}$ accumulation and cell death indeed occurred in rice premature senescence leaf 85 (psl85) mutant [34]. The content of protein was lower in undifferentiated upper spikelets of $p t s d 1$ compared to that of WT, the oxidative damage and cell death caused by $\mathrm{H}_{2} \mathrm{O}_{2}$ accumulation were enhanced. These phenotypes of $p t s d 1$ were consistent with senescence.

\subsection{Senescence Related Signal Response are Activated in ptsd1}

\subsubsection{Hormone Signaling}

Plant senescence is regulated by hormone homeostasis [35,36]. Plant CK levels are reduced during natural senescence, and CKs play a senescence-retarding role in plants [37]. The CK content of the transgenic Arabidopsis overexpression of CK oxidase/dehydrogenase (AtCKX) gene is reduced, which results in diminished activity of the vegetative and floral shoot apical meristems [38]. In our study, the CK content was reduced in ptsd1. Meanwhile, the expressions of nuclear localized Arabidopsis response regulator (ARR) like genes, which regulate the transcription of CK target genes [39], were lowly expressed in $p t s d 1$. These data demonstrated that the CK signaling was repressed in $p t s d 1$.

In addition to CKs, ET also plays a pivotal role in plant senescence. In our study, ET biosynthesis, response and signaling related genes were highly expressed in ptsd1. The 1-aminocyclopropane-1-carboxylic acid (ACC) synthase is a key enzyme in ET biosynthesis from the methionine, when expression of ACC synthase gene is enhanced, senescence of several plant species is activated [40]. The ACC synthase genes were highly expressed in $p t s d 1$ (Figure S4A). Meanwhile, ET signaling related genes ethylene responsive 1 and EIN3 were activated (Figure S4A). EIN3 is a SAG gene. The activity of EIN3 can be enhanced by ET that promotes leaf senescence [25].

\subsection{2. $\mathrm{Ca}^{2+}$ Signaling}

The main symptoms of plant senescence are the dramatic increases in ROS [41]. The content of $\mathrm{H}_{2} \mathrm{O}_{2}$ was significantly increased in ptsd1-YS. Elevation of intracellular $\mathrm{Ca}^{2+}$ is essential for the $\mathrm{H}_{2} \mathrm{O}_{2}$ accumulation [42]. Normal cell function requires maintenance a low cytosolic $\mathrm{Ca}^{2+}$ concentration. $\mathrm{Ca}^{2+}$ concentration increases in the senescence processes [43] and $\mathrm{Ca}^{2+}$ influx is related to cell death [44]. In our study, $\mathrm{Ca}^{2+}$ signal transduction related genes were activated, such as cyclic nucleotide-gated ion channel protein genes which can mediate the initiation of the developmentally regulated cell death programs in a $\mathrm{Ca}^{2+}$ dependent manner [45], CDPK genes which participate in $\mathrm{Ca}^{2+}$ signal transduction, Rboh genes which can mediate the generation of superoxide through calcium-dependent NADPH oxidase were highly expressed in $p t s d 1$.

\subsubsection{TFs}

Many TFs play pivotal roles in plant senescence, such as the members of NAC and WRKY families [46]. These TFs have been functionally characterized in plant senescence, such as AtORE1 [47], AtNAP [48], TtNAM-B1 [49], AtWRKY53 [50] and AtWRKY70 [51]. Similarly, some WRKY and NAC TF genes were highly expressed in $p t s d 1$ (Figure S5). In contrast, the MADS-box floral homeotic genes were depressed in ptsd1. The E-class MADS-box genes TaSEP5 and TaSEP6 were the homologous genes of OsMADS34 and OsMADS5 in rice (Table S10). Genetic and molecular analyses demonstrated that 
OsMADS5 and OsMADS34 together regulate floral meristem determinacy by positively regulating the other homeotic genes in rice [52]. In $p t s d 1$, the functions of the homeotic genes need further research.

\subsection{Senescence Related Metabolisms are Activated in ptsd1}

The degradation of molecules such as proteins, lipids, nucleotides, and polysaccharides is a typical feature of senescence that occurs at the final phase of leaf development [53]. In our study, this process was reflected by the high expressions of several catabolism-related genes. Degradation of macromolecules, especially the proteins via the ubiquitin-proteasome system [54] was enhanced in ptsd1. Macromolecules were degraded and $\mathrm{N}$ was released in the form of $\mathrm{NH}_{4}{ }^{+}$in $p t s d 1$. Nitrogen is exported from senescing barley and wheat leaves as glutamate, but also as aspartate and threonine [18,55]. The relative abundance of glutamine increases during late senescence in wheat phloem [56]. The GS and asparagine synthetase genes, which participate in the $\mathrm{N}$ assimilation and remobilization [55] were highly expressed in ptsd1. Glutamine is the major mobile amino acid involved in the long-distance transport of $\mathrm{N}$ [57]. The degradation of macromolecules might be transported to other organs for recycling in the form of glutamine. SAGs are enriched in the biosynthesis of phenylpropanoids during the leaf senescence in sorghum (Sorghum bicolor) [58]. The phenylalanine ammonia-lyase genes, which encode the key enzyme in phenylpropanoid metabolic pathway, were highly expressed in $p t s d 1$. The anthocyanin and lignin biosynthesis pathways were activated in ptsd1 (Figure 8B), and the content of lignin was significantly increased in $p t s d 1$.

All these data suggested that there were five key senescence related metabolisms were activated in ptsd1 (Figure 8): (1) The proteins, lipids, polysaccharides and nucleotides were degraded; (2) The macromolecules degradation increased ammonium accumulation; (3) The ammonium was assimilated in the form of glutamine and aspartate; (4) The phenylalanine flowed into phenylpropanoid metabolic pathway as a result of some secondary metabolites biosynthesis, such as anthocyanin and lignin, and (5) GST catalyzed the reaction of glutathione with a wide variety of organic compounds to form R-S-glutathione, a process that was essential for the transport of a variety of metabolites.

\subsection{The miRNAs Participate in Senescence Related Biological Process in ptsd1}

Several studies have shown that microRNAs regulate plant senescence [59]. A conserved microRNA, miR164, is identified as a negative regulator of senescence [24]. ET enhances the activity of EIN3, EIN3 induces NAC2 expression by directly repressing miR164 transcription, miR164 mediates the cleavage of NAC2 and ultimately regulates the expression of a large set of $S A G s$ through the feed-forward signaling cascade comprising EIN3, miR164, and NAC [24,25]. In this study, ET signaling related genes EIN3 and TF genes in NAC family were activated, while tae-miR164 was lowly expressed in $p t s d 1$ (Figure S13). A novel microRNA, novel-miR49, was extensively involved in senescence related biological process by regulating 14 target genes (Figure S13). WRKY TFs play pivotal roles in leaf senescence [46], WRKY genes were regulated by seven microRNAs including novel-miR49 (Figure S13).

\subsection{A Hypothesis of The Molecular Regulatory Network in ptsd1}

In summary, we put forward a hypothesis of a molecular regulatory network in ptsd1 (Figure 10): (1) The endogenous hormone ET is increased and CK is decreased, intracellular $\mathrm{Ca}^{2+}$ concentration is increased; (2) The abnormal phytohormones and $\mathrm{Ca}^{2+}$ signal are transduced through their respective signaling pathways; (3) The expressions of many SAGs are activated and some homeotic genes are depressed; (4) The meristem characteristics of the undifferentiated spikelet primordia are absent and senescence related metabolisms, including the degradation of macromolecules, $\mathrm{N}$ recycling, anthocyanin and lignin biosynthesis, and ROS accumulation, are activated.

Based on the research data of phenotype, metabolism, transcriptome and miRNome, we speculated that the activated senescence related process led to the upper spikelet primordia terminating differentiation in the end. However, the exquisite molecular genetic mechanism of the wheat spike differentiation requires further study. 


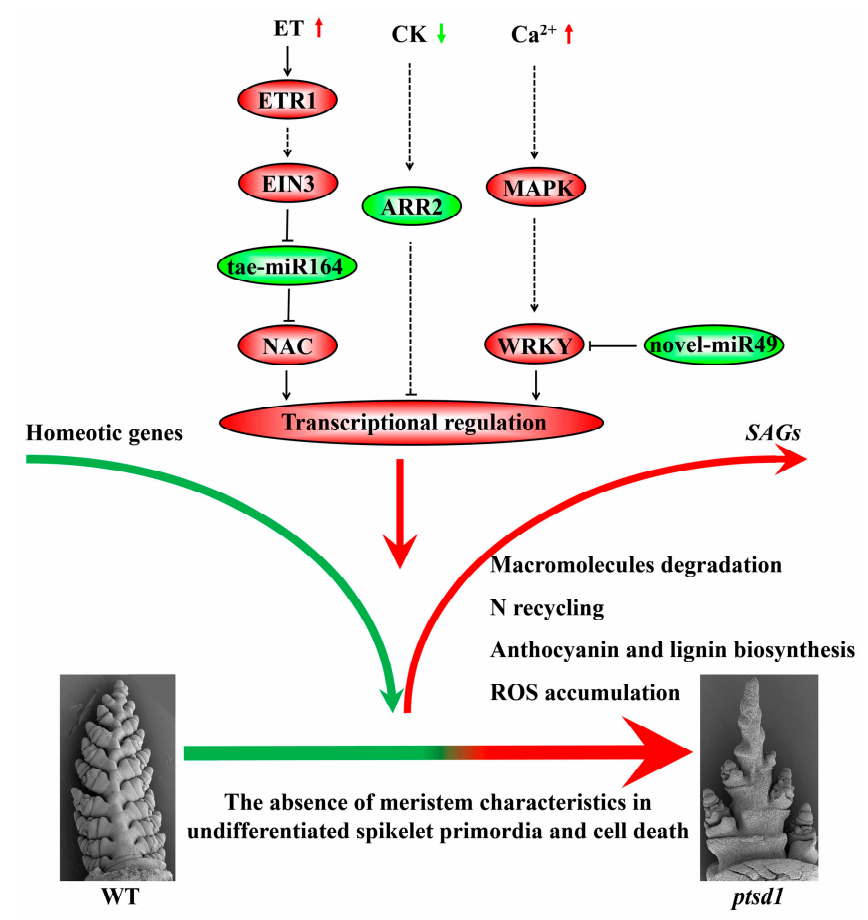

Figure 10. A hypothesis of molecular regulatory network in $p t s d 1$. The modules coloured in red are highly expressed in ptsd1-YS and modules coloured in green are lowly expressed in $p t s d 1-Y S$. The real lines indicate the direct interaction, the dotted lines indicate the indirect interaction.

\section{Materials and Methods}

\subsection{Plant Materials and Growth Conditions}

The wheat cultivar "Guomai 301" was bred in our laboratory. The seeds of WT were treated with EMS and planted in Shangqiu Experimental Farm, Henan Province, China $\left(34^{\circ} 25^{\prime} \mathrm{N}, 115^{\circ} 39^{\prime} \mathrm{E}\right.$, $49 \mathrm{~m}$ asl) in 2012-2015. The mutant ptsd1 was obtained at $\mathrm{M}_{2}$ generation in 2014-2015 growing season. Mutant lines of $p t s d 1$ had truncated spikes without segregating at $\mathrm{M}_{3}$ generation in 2015-2016 growing season, which primarily indicated that the phenotype was controlled by recessive genes. The field experiments were carried out in a completely randomized design as described by Duan et al. [60].

\subsection{Morphological Observation and Analysis}

Tiller number, spike number, plant height, internode number of the main stem and etc. of $p t s d 1$ and WT were observed and measured. Each genotype sample was prepared by random taking ten individuals. The young spikes were observed as described by He et al. [61]. For observation with scanning electron microscope, young spikes were fixed in $1 \%$ osmic acid solution prepared in $0.1 \mathrm{~mol} / \mathrm{L}$ phosphate buffer at $\mathrm{pH} 7.4$ for one hour, dehydrated in a graded ethyl alcohol series for fifteen minutes in each solution, and critical point dried using $\mathrm{CO}_{2}$. The dried tissues coated with platinum were observed and photographed using a scanning electron microscope (SU8010, Hitachi, Tokyo, Japan).

\subsection{RNA Extraction, $m R N A$ and miRNA Sequencing}

The young spikes at late double ridge stage [28] and young stem tips (short stem fragment just connected with young spikes) of WT and mutant $p t s d 1$ were identified and sampled for RNA extraction [62]. Total RNAs of WT and mutant $p t s d 1$ plants were extracted with TRIzol ${ }^{\circledR}$ reagent (TransGen Biotech, Beijing, China). All the samples for mRNA and miRNA sequencing had three biological replicates. RNA sequencing and basic analysis were carried out in BioMarker Company (Beijing, China). Sequences have been deposited at the Sequence Read Archive of the National Center for Biotechnology under BioProject numbers PRJNA553833 and PRJNA554945. 


\section{4. mRNA Data Analysis}

The clean reads were mapped to the reference wheat genome (ftp://ftp.ensemblgenomes.org/ pub/plants/release-32/fasta/triticum_aestivum; access date: 8 September 2016) using Tophat2 tool software [63]. Gene functional annotation was carried out as described by He et al. [61]. Gene expression levels were estimated by FPKM [64]. DEGs between two sample groups were analyzed using the DESeq R package [65]. The FDR $<0.01$ (false discovery rate) and FC $\geq 2$ (fold change) were set as the thresholds for significantly DEGs.

Pearson's correlation coefficient between biological replicates was calculated using the RPKM values [66]. The $k$-means cluster was performed on the BMKCloud platform (https://www.biocloud.net/) with DEGs (FDR $<0.01$ and FC $\geq 4$ ). For the single gene, heat maps were drawn using the software HemI (http://hemi.biocuckoo.org; access date: 5 November 2014) according to the FPKM values. For the overall trend of the DEGs in the families, heat maps were drawn according to the average FPKM values in a family.

\section{5. miRNA Data Analysis}

The clean reads were used to identify known miRNAs and predict novel miRNAs by comparing with known miRNAs from miRBase 21 (http://www.mirbase.org; access date: 3 July 2014). The miRNA expression levels were defined as "counts of reads mapped to miRNA $\times 1,000,000$ "/"reads mapped to the reference genome" (TPM) [67]. Differentially expressed miRNAs (FDR $\leq 0.05$ and FC $\geq 2$ ) between samples were screened out using DESeq software (BioMarker, Beijing, China) [68].

The miRNA target gene prediction was performed using TargetFinder [69]. Briefly, miRNA sequences matched to the reference mRNA sequences and potential targets were computationally predicted by the match/mismatch-scoring ratio. Mismatched pairs were scored as 1, and G:U pairs were scored as 0.5 . Only predicted targets with scores less than four were considered reasonable.

\section{6. $q R T-P C R s$ of $m R N A s$ and miRNAs}

The qRT-PCR was performed as described by He et al. [61]. For miRNA, reverse transcription was performed with $1 \mu \mathrm{g}$ RNA using the miScript reverse transcriptase mix (Qiagen, Beijing, China) according to the manufacturer's protocol. The miRNA specific forward primer is the same as the mature miRNA sequence. U6 was used as an internal control. Real-time PCRs of miRNAs were performed using the miScript SYBR Green PCR kit (Qiagen, Beijing, China) with the specific primers and the universal primer provided in the kit following the production instructions. All primer sequences are listed in Table S25.

\subsection{Histochemical Observations}

The young spikes of WT and mutant ptsd1 were fixed in FAA solution $(5 \mathrm{~mL}$ of formalin, $5 \mathrm{~mL}$ of acetic acid and $90 \mathrm{~mL}$ of $70 \%$ ethyl alcohol). The samples were dehydrated, embedded in paraffin and sectioned with a rotary microtome as described by Geng et al. [70]. The cell morphology was observed after the tissues were stained with saffron and solid green (G1031, Servicebio, Wuhan, China). The distributions of starch and protein were observed after the tissues were stained with Periodic Acid-Schiff and Naphthol Yellow S (G1068, Servicebio, Wuhan, China). Photos were taken with a camera (Nikon Eclipse E100, Tokyo, Japan) and analyzed with CaseViewer software.

\subsection{TUNEL Assays}

The sections of the young spikes of WT and mutant ptsd1 at late double ridge stage were prepared as described by Phan et al. [71]. The terminal deoxynucleotidyl transferase-mediated dUTP-biotin nick end labeling (TUNEL) assay was performed using a kit (Fluorescein In Situ Cell Death Detection Kit; Roche, Indianapolis, IN, USA) according to the manufacturer's instructions. The green fluorescence of 
fluorescein and blue fluorescence of $4^{\prime}, 6$-diamidino-2-phenylindole (DAPI) in the tissues were activated and observed under a fluorescence scanning confocal microscope (Nikon Eclipse Ti-SR).

\subsection{Determination of Metabolic Indicators}

The young spikes of WT and mutant $p t s d 1$ at late double ridge stage were dissected out, frozen immediately in liquid nitrogen and stored at $-80^{\circ} \mathrm{C}$. The contents of $\mathrm{ZA}$, total protein, total sugar, nitrate nitrogen and ammonium nitrogen $\left(\mathrm{NH}^{4+}\right)$, lignin and $\mathrm{H}_{2} \mathrm{O}_{2}$ and the activities of glutathione $S$-transferase, glutamine synthetase and chitinase were measured. Each measurement was repeated for three times. The phenotyping of the 10 physiological traits were performed using different assay kits according to the manufacturer's instructions in Comin Biotechnology Co., Ltd. (Suzhou, China). The detail calculation formulas and results were described in Table S26.

\subsubsection{Determination of ZA Content}

The ZA of young spikes was extracted from $100 \mathrm{mg}$ freeze-dried meal in $1 \mathrm{~mL}$ mixed solution (carbinol: $0.5 \%$ acetic acid $=80: 20$ ) at $4{ }^{\circ} \mathrm{C}$ overnight, centrifuged at $8000 \times g$ for $10 \mathrm{~min}$. The sample was decolored by adding $0.5 \mathrm{~mL}$ petroleum ether for three times, discarded the supernatant petroleum ether. The $\mathrm{pH}$ value was adjusted to 8 , then extracted with acetic ether for three times, combined the supernatant organic phases and blew dry with a nitrogen blower at $60{ }^{\circ} \mathrm{C}$. The sample was ready to determine by adding $0.5 \mathrm{~mL}$ mobile phase solution and filtered with a needle filter. ZA was determined by HPLC (Agilent 1100) system with a Kromasil C18 $(250 \mathrm{~mm} \times 4.6 \mathrm{~mm}, 5 \mu \mathrm{m})$ reversion phase chromatography column at $35^{\circ} \mathrm{C}$. The mobile phase composed of carbinol and $1 \%$ acetic acid solution $(4: 6, v / v)$ at a flow rate of $0.8 \mathrm{~mL} / \mathrm{min}$, and the UV absorbance was monitored at $254 \mathrm{~nm}$. The chromatography elution profiles of the standard ZA and a sample were shown in Table S26.

\subsubsection{Determination of Soluble Protein and Total Sugar Contents}

The soluble proteins of WT and mutant ptsd1 were extracted using $100 \mathrm{mg}$ young spikes in a $50 \mathrm{mM}$ cold potassium-phosphate solution at $\mathrm{pH} 7.0$, centrifuged at $10,000 \times \mathrm{g}$ at $4{ }^{\circ} \mathrm{C}$ for $15 \mathrm{~min}$. The supernatant was used to quantify the soluble protein. The soluble protein content was determined with the colorimetric assay described by Smith et al. [72].

The sugars of each sample were extracted from $100 \mathrm{mg}$ freeze-dried meal. $1 \mathrm{~mL}$ of $6 \mathrm{M} \mathrm{HCl}$ was added to each sample, heated in water bath at $95^{\circ} \mathrm{C}$ for $30 \mathrm{~min}$, then added $1 \mathrm{~mL}$ of $100 \mathrm{~g} / \mathrm{L} \mathrm{NaOH}$, mixed by vortex, centrifuged at $8000 \times g$ for $10 \mathrm{~min}$. The supernatant was used for quantification of the total sugars. The sugars were quantified using 3,5-dinitrosalicylic acid method described by Breuil and Saddler [73].

\subsubsection{Determination of Nitrate Nitrogen and Ammonium Nitrogen Content}

The nitrate nitrogen and ammonium nitrogen of young spikes were extracted from $100 \mathrm{mg}$ freeze-dried meal in $1 \mathrm{~mL}$ of distilled water at $90{ }^{\circ} \mathrm{C}$ for $30 \mathrm{~min}$. The nitrate nitrogen content of the solution was quantified spectrophotometrically after mixing $0.02 \mathrm{~mL}$ of solution with $10 \%(w / v)$ salicylic acid in $96 \%$ sulfuric acid [74]. The ammonium content was determined with the colorimetric assay described by Krom [75].

\subsubsection{Determination of $\mathrm{H}_{2} \mathrm{O}_{2}$ Content}

The $\mathrm{H}_{2} \mathrm{O}_{2}$ was extracted using $100 \mathrm{mg}$ young spikes in the dark in $3 \mathrm{~mL}$ of $25 \mathrm{mM}$ phosphate solution, $\mathrm{pH} 7.0$, containing $0.05 \%$ guaiacol and 2.5 units horseradish peroxidase at $25^{\circ} \mathrm{C}$ for $2 \mathrm{~h}$. Absorbance of the solution was measured at $450 \mathrm{~nm}$ as described by Tiedemann [76]. 


\subsubsection{Determination of Lignin Content}

The young spikes of WT and mutant ptsd1 were dried in an air-forced oven at $80{ }^{\circ} \mathrm{C}$. Two milligrams of the dried tissue were ground into fine powder and homogenized in $0.5 \mathrm{~mL}$ of $25 \%(\mathrm{v} / \mathrm{v})$ acetyl bromide in glacial acetic acid at $80^{\circ} \mathrm{C}$ for $40 \mathrm{~min}$. And then the extraction solution was mixed with $0.5 \mathrm{~mL}$ of acetic acid. The supernatant was used for quantification of total lignin. Analysis of lignin content was carried out according to the method described by Li et al. [77].

\subsubsection{Determination of GST Activity}

The young spikes of WT and mutant $p t s d 1$ were homogenized in $1 \mathrm{~mL}$ of $0.1 \mathrm{M}$ sodium phosphate solution, and centrifuged at $8000 \times g$ for $10 \mathrm{~min}$. The supernatant was used for determination of GST activity. A total of $220 \mu \mathrm{L}$ solution (supernatant, $20 \mu \mathrm{L}$; 1-chloro-2,4-nitrobenzene solution, $180 \mu \mathrm{L}$; glutathione solution $20 \mu \mathrm{L}$ ) was prepared for determination of GST activity, and then the absorbance was determined and recorded as A1, A2 at the time point $10 \mathrm{~s}, 310 \mathrm{~s}$ respectively with a spectrometer at $340 \mathrm{~nm}$. Detailed calculation formulas and results are described in Table S26.

\subsubsection{Determination of Total GS Activity}

One-hundred milligrams frozen young spikes were homogenized in $1 \mathrm{~mL}$ of extraction solution containing $50 \mathrm{mM}$ Tris- $\mathrm{HCl}$ ( $\mathrm{pH}$ 8.0), $2 \mathrm{mM} \mathrm{MgSO}_{4}, 0.4 \mathrm{M}$ sucrose, $2 \mathrm{mM}$ dithiothreitol. The homogenate was centrifuged at $8000 \times g$ at $4{ }^{\circ} \mathrm{C}$ for $10 \mathrm{~min}$. The supernatant was used for determination of GS activity. The GS activity was determined according to the modified method of Yu et al. [78].

\subsubsection{Determination of Chitinase Activity}

One-hundred milligrams frozen young spikes were homogenized in $1 \mathrm{~mL}$ of $10 \mathrm{mM}$ sodium acetate solution ( $\mathrm{pH}$ 5.0) and centrifuged at 10,000 $\times \mathrm{g}$ for $20 \mathrm{~min}$. The supernatant was used for the determination of chitinase activity. The enzymatic activity was determined spectrophotometrically by measuring the reaction products from the chitinase-catalyzed hydrolysis of chitin at $585 \mathrm{~nm}$ as described by Mohammadi et al. [79].

Supplementary Materials: Supplementary materials can be found at http:/www.mdpi.com/1422-0067/20/18/ 4642/s1. Figure S1: Illustration of the proposed scales of wheat spike differentiation of WT (A-F) and mutant ptsd1 (G-L); Figure S2: Spike histological sections of WT and mutant ptsd1; Figure S3: Principal components analysis and DEGs among four samples; Figure S4: Heatmap of the DEGs in hormone pathways and the content of ZA in young spikes of WT and ptsd1; Figure S5: Hierarchical cluster analyses of the differentially expressed TF gene families; Figure S6: Cluster and expression pattern of the DEGs in MADS-box family; Figure S7: The DEGs in gene families of receptor-like kinases, protein kinases, phosphatases and calcium signaling between WT-YS and ptsd1-YS; Figure S8: ROS signaling in ptsd1; Figure S9: Heatmap of DEG families involved in macromolecule degradation (A), nutrient transport (B), $\mathrm{N}$ recycling (C) and secondary metabolites biosynthesis (D) between WT-YS and ptsd1-YS; Figure S10: The distribution of starch (red) and protein (yellow) in wheat spike apexes of WT (A) and mutant ptsd1 (B) at initiation of second awn stage; Figure S11: Heatmap of the DEGs encoding GST and glutathione-conjugate transporter; Figure S12: K-means clusters of the differentially expressed miRNAs and the qRT-PCR verifying; Figure S13: DE miRNAs and their targets involved in senescence related signal responses and metabolisms in mutant ptsd1; Table S1: Comparison of the agronomic traits between WT and mutant ptsd1; Table S2-S20: The detailed information of the mRNA-seq data; Table S21-S24: The detailed information of the miRNA-seq data; Table S25: The DNA sequences of the primers used in this study; Table S26: The detail calculation formulas and results of the physiological trait determination.

Author Contributions: Z.J. performed all the experiments and analyzed the data. Y.N. and X.H. selected the mutant. J.L., J.A., Y.S., H.L. and J.Z. helped with sowing and sample preparation. Y.J. and Q.L. contributed to the field experiments and maintenance of the wheat accessions. J.N. designed the whole study and drafted the manuscript and gave the final approval to the version of the manuscript that is being sent for consideration for publication.

Funding: This research was funded by the National Natural Science foundation of China (NSFC), grant number 31571646, Science and Technology Project in Henan Province, grant number 182102110147 and the Special Fund for Key Agricultural Projects in Henan Province, China, grant number 161100110400.

Conflicts of Interest: The authors declare that the research was conducted in the absence of any commercial or financial relationships that could be construed as a potential conflict of interest. 


\section{References}

1. Waddington, S.R.; Cartwright, P.M.; Wall, P.C. A quantitative scale of spike initial and pistil development in barley and wheat. Ann. Bot. 1983, 51, 119-130. [CrossRef]

2. Murai, K.; Miyamae, M.; Kato, H.; Takumi, S.; Ogihara, Y. WAP1, a wheat APETALA1 homolog, plays a central role in the phase transition from vegetative to reproductive growth. Plant Cell Physiol. 2003, 44, 1255-1265. [CrossRef] [PubMed]

3. Guo, H.; Yan, Z.; Li, X.; Xie, Y.; Xiong, H.; Liu, Y.; Zhao, L.; Gu, J.; Zhao, S.; Liu, L. Development of a high-efficient mutation resource with phenotypic variation in hexaploid winter wheat and identification of novel alleles in the TaAGP.L-B1 gene. Front. Plant Sci. 2017, 8, 1404. [CrossRef] [PubMed]

4. Rijpkema, A.S.; Vandenbussche, M.; Koes, R.; Heijmans, K.; Gerats, T. Variations on a theme: Changes in the floral ABCs in angiosperms. Semin. Cell Dev. Biol. 2010, 21, 100-107. [CrossRef] [PubMed]

5. Yoshida, H.; Nagato, Y. Flower development in rice. J. Exp. Bot. 2011, 62, 4719-4730. [CrossRef] [PubMed]

6. Murai, K. Homeotic genes and the ABCDE model for floral organ formation in wheat. Plants 2013, 2, 379-395. [CrossRef] [PubMed]

7. Malcomber, S.T.; Kellogg, E.A. Heterogeneous expression patterns and separate roles of the SEPALLATA gene LEAFY HULL STERILE1 in grasses. Plant Cell 2004, 16, 1692-1706. [CrossRef] [PubMed]

8. Shitsukawa, N.; Takagishi, A.; Ikari, C.; Takumi, S.; Murai, K. WFL, a wheat FLORICAULA/LEAFY ortholog, is associated with spikelet formation as lateral branch of the inflorescence meristem. Genes Genet. Syst. 2006, 81, 13-20. [CrossRef] [PubMed]

9. Shaw, L.M.; Lyu, B.; Turner, R.; Li, C.; Chen, F.; Han, X.; Fu, D.; Dubcovsky, J. FLOWERING LOCUS T2 regulates spike development and fertility in temperate cereals. J. Exp. Bot. 2019, 70, 193-204. [CrossRef]

10. Debernardi, J.M.; Lin, H.; Chuck, G.; Faris, J.D.; Dubcovsky, J. MicroRNA172 plays a crucial role in wheat spike morphogenesis and grain threshability. Development 2017, 144, 1966-1975. [CrossRef]

11. Liu, P.; Liu, J.; Dong, H.; Sun, J. Functional regulation of Q by microRNA172 and transcriptional co-repressor TOPLESS in controlling bread wheat spikelet density. Plant Biotechnol. J. 2018, 16, 495-506. [CrossRef] [PubMed]

12. Patel, R.; Mohapatra, P.K. Regulation of spikelet development in rice by hormones. J. Exp. Bot. 1992, 43, 257-262. [CrossRef]

13. Yoshida, A.; Ohmori, Y.; Kitano, H.; Taguchi-Shiobara, F.; Hirano, H.Y. Aberrant spikelet and panicle1, encoding a TOPLESS-related transcriptional co-repressor, is involved in the regulation of meristem fate in rice. Plant J. 2012, 70, 327-339. [CrossRef] [PubMed]

14. Serek, M.; Jones, R.B.; Reid, M.S. Role of ethylene in opening and senescence of gladiolus sp. flowers. J. Am. Soc. Hort. 1994, 119, 1014-1019. [CrossRef]

15. Lawton, K.A.; Raghothana, K.G.; Goldsbrough, P.B.; Woodson, W.R. Regulation of senescence-related gene expression in carnation flower petals by ethylene. Plant Physiol. 1990, 93, 1370-1375. [CrossRef] [PubMed]

16. Yang, J.; Zhang, J.; Wang, Z.; Liu, K.; Wang, P. Post-anthesis development of inferior and superior spikelets in rice in relation to abscisic acid and ethylene. J. Exp. Bot. 2006, 57, 149-160. [CrossRef]

17. Gepstein, S.; Sabehi, G.; Carp, M.J.; Hajouj, T.; Nesher, M.F.; Yariv, I.; Dor, C.; Bassani, M. Large-scale identification of leaf senescence-associated genes. Plant J. 2003, 36, 629-642. [CrossRef] [PubMed]

18. Gregersen, P.L.; Holm, P.B.; Krupinska, K. Leaf senescence and nutrient remobilisation in barley and wheat. Plant Biol. 2008, 10, 37-49. [CrossRef]

19. Zhang, Q.; Xia, C.; Zhang, L.; Dong, C.; Liu, X.; Kong, X. Transcriptome analysis of a premature leaf senescence mutant of common wheat (Triticum aestivum L.). Int. J. Mol. Sci. 2018, 19, 782. [CrossRef]

20. Kim, H.J.; Nam, H.G.; Lim, P.O. Regulatory network of NAC transcription factors in leaf senescence. Curr. Opin. Plant Biol. 2016, 33, 48-56. [CrossRef]

21. Zhang, H.; Zhao, M.; Song, Q.; Zhao, L.; Wang, G.; Zhou, C. Identification and function analyses of senescence-associated WRKYs in wheat. Biophys. Res. Commun. 2016, 474, 761-767. [CrossRef] [PubMed]

22. Uauy, C.; Distelfeld, A.; Fahima, T.; Blechl, A.; Dubcovsky, J. A NAC gene regulating senescence improves grain protein, zinc, and iron content in wheat. Science 2006, 314, 1298-1301. [CrossRef] [PubMed]

23. Wang, W.; Hao, Q.; Tian, F.; Li, Q.; Wang, W. The stay-green phenotype of wheat mutant tasg1 is associated with altered cytokinin metabolism. Plant Cell Rep. 2016, 35, 585-599. [CrossRef] [PubMed] 
24. Kim, J.H.; Woo, H.R.; Kim, J.; Lim, P.O.; Lee, I.C.; Choi, S.H.; Hwang, D.; Nam, H.G. Trifurcate feed-forward regulation of age-dependent cell death involving miR164 in Arabidopsis. Science 2009, 323, 1053-1057. [CrossRef] [PubMed]

25. Li, Z.; Peng, J.; Wen, X.; Guo, H. ETHYLENE-INSENSITIVE3 is a senescence-associated gene that accelerates age-dependent leaf senescence by directly repressing miR164 transcription in Arabidopsis. Plant Cell 2013, 25, 3311-3328. [CrossRef] [PubMed]

26. Ni, Y.; Zhu, P.; Liu, H.; Hu, X.; Li, Q.; Niu, J. Construction and analysis of EMS induced mutant library of new wheat cultivar guomai 301. J. Henan Agric. Sci. 2015, 44, 42-45. [CrossRef]

27. Sun, Y.; Zhu, X.; He, R.; Li, J.; An, J.; Jiao, Z.; Jiang, Y.; Li, Q.; Niu, J. Seletion and indentification of the EMS-induced wheat mutants from Shengnong 1. J. Triticeae Crops 2018, 38, 782-790.

28. Vahamidis, P.; Karamanos, A.; Economou, G.; Fasseas, C. A new scale for the assessment of wheat spike morphogenesis. Ann. Appl. Biol. 2014, 164, 220-231. [CrossRef]

29. Gan, S. Mitotic and postmitotic senescence in plants. Sci. Aging Knowl. Environ. 2003, 38. [CrossRef]

30. Gan, S. Concepts and types of senescence in plants. Methods Mol. Biol. 2018, 1744, 3-8. [CrossRef]

31. Hensel, L.L.; Nelson, M.A.; Richmond, T.A.; Bleecker, A.B. The fate of inflorescence meristems is controlled by developing fruits in Arabidopsis. Plant Physiol. 1994, 106, 863-876. [CrossRef] [PubMed]

32. Fischer, A.; Feller, U. Senescence and protein degradation in leaf segments of young winter wheat: Influence of leaf age. J. Exp. Bot. 1994, 45, 103-109. [CrossRef]

33. Bieker, S.; Riester, L.; Stahl, M.; Franzaring, J.; Zentgraf, U. Senescence-specific alteration of hydrogen peroxide levels in Arabidopsis thaliana and oilseed rape spring variety Brassica napus L. Cv. Mozart. J. Integr. Plant Biol. 2012, 54, 540-554. [CrossRef] [PubMed]

34. He, Y.; Zhang, Z.; Li, L.; Tang, S.; Wu, J.L. Genetic and physio-biochemical characterization of a novel premature senescence leaf mutant in rice (Oryza sativa L.). Int. J. Mol. Sci. 2018, 19, 2339. [CrossRef] [PubMed]

35. Delatorre, C.A.; Cohen, Y.; Liu, L.; Peleg, Z.; Blumwald, E. The regulation of the SARK promoter activity by hormones and environmental signals. Plant Sci. 2012, 193, 39-47. [CrossRef] [PubMed]

36. Khan, M.; Rozhon, W.; Poppenberger, B. The role of hormones in the aging of plants: A mini-review. Gerontology 2014, 60, 49-55. [CrossRef] [PubMed]

37. Riefler, M.; Novak, O.; Strnad, M.; Schmülling, T. Arabidopsis cytokinin receptor mutants reveal functions in shoot growth, leaf senescence, seed size, germination, root development, and cytokinin metabolism. Plant Cell 2006, 18, 40-54. [CrossRef]

38. Werner, T.; Motyka, V.; Laucou, V.; Smets, R.; Van Onckelen, H.; Schmülling, T. Cytokinin-deficient transgenic Arabidopsis plants show multiple developmental alterations indicating opposite functions of cytokinins in the regulation of shoot and root meristem activity. Plant Cell 2003, 15, 2532-2550. [CrossRef] [PubMed]

39. Kim, H.J.; Ryu, H.; Hong, S.H.; Woo, H.R.; Lim, P.O.; Lee, I.C.; Sheen, J.; Nam, H.G.; Hwang, I. Cytokinin-mediated control of leaf longevity by AHK3 through phosphorylation of ARR2 in Arabidopsis. Proc. Natl. Acad. Sci. USA 2006, 103, 814-819. [CrossRef]

40. Jing, H.C.; Schippers, J.H.; Hille, J.; Dijkwel, P.P. Ethylene-induced leaf senescence depends on age-related changes and OLD genes in Arabidopsis. J. Exp. Bot. 2005, 56, 2915-2923. [CrossRef]

41. Leshem, Y.Y. Plant senescence processes and free radicals. Free Radic. Biol. Med. 1988, 5, 39-49. [CrossRef]

42. Hu, X.; Neill, S.J.; Yang, Y.; Cai, W. Fungal elicitor Pep-25 increases cytosolic calcium ions, $\mathrm{H}_{2} \mathrm{O}_{2}$ production and activates the octadecanoid pathway in Arabidopsis thaliana. Planta 2009, 229, 1201-1208. [CrossRef] [PubMed]

43. Ferguson, I.B. Calcium in plant senescence and fruit ripening. Plant Cell Environ. 1984, 7, 477-489. [CrossRef]

44. Errakhi, R.; Dauphin, A.; Meimoun, P.; Lehner, A.; Reboutier, D.; Vatsa, P.; Briand, J.; Madiona, K.; Rona, J.P.; Barakate, M.; et al. An early $\mathrm{Ca}^{2+}$ influx is a prerequisite to thaxtomin A-induced cell death in Arabidopsis thaliana cells. J. Exp. Bot. 2008, 59, 4259-4270. [CrossRef] [PubMed]

45. Urquhart, W.; Gunawardena, A.H.; Moeder, W.; Ali, R.; Berkowitz, G.A.; Yoshioka, K. The chimeric cyclic nucleotide-gated ion channel ATCNGC11/12 constitutively induces programmed cell death in a $\mathrm{Ca}^{2+}$ dependent manner. Plant Mol. Biol. 2007, 65, 747-761. [CrossRef] [PubMed]

46. Breeze, E.; Harrison, E.; McHattie, S.; Hughes, L.; Hickman, R.; Hill, C.; Kiddle, S.; Kim, Y.S.; Penfold, C.A.; Jenkins, D.; et al. High-resolution temporal profiling of transcripts during Arabidopsis leaf senescence reveals a distinct chronology of processes and regulation. Plant Cell 2011, 23, 873-894. [CrossRef] [PubMed] 
47. Matallana-Ramirez, L.P.; Rauf, M.; Farage-Barhom, S.; Dortay, H.; Xue, G.P.; Dröge-Laser, W.; Lers, A.; Balazadeh, S.; Mueller-Roeber, B. NAC transcription factor ORE1 and senescence-induced BIFUNCTIONAL NUCLEASE1 (BFN1) constitute a regulatory cascade in Arabidopsis. Mol. Plant 2013, 6, 1438-1452. [CrossRef] [PubMed]

48. Guo, Y.; Gan, S. AtNAP, a NAC family transcription factor, has an important role in leaf senescence. Plant J. 2006, 46, 601-612. [CrossRef] [PubMed]

49. Jamar, C.; Loffet, F.; Frettinger, P.; Ramsay, L.; Fauconnier, M.L.; Jardin, P.D. NAM-1 gene polymorphism and grain protein content in Hordeum. J. Plant Physiol. 2010, 167, 497-501. [CrossRef]

50. Miao, Y.; Zentgraf, U. The antagonist function of Arabidopsis WRKY53 and ESR/ESP in leaf senescence is modulated by the jasmonic and salicylic acid equilibrium. Plant Cell 2007, 19, 819-830. [CrossRef]

51. Besseau, S.; Li, J.; Palva, E.T. WRKY54 and WRKY70 co-operate as negative regulators of leaf senescence in Arabidopsis thaliana. J. Exp. Bot. 2012, 63, 2667-2679. [CrossRef] [PubMed]

52. Wu, D.; Liang, W.; Zhu, W.; Chen, M.; Ferrándiz, C.; Burton, R.A.; Dreni, L.; Zhang, D. Loss of LOFSEP transcription factor function converts spikelet to leaf-like structures in rice. Plant Physiol. 2018, 176, 1646-1664. [CrossRef] [PubMed]

53. Guo, Y.; Cai, Z.; Gan, S. Transcriptome of Arabidopsis leaf senescence. Plant Cell Environ. 2004, 27, 521-549. [CrossRef]

54. Carrión, C.A.; Costa, M.L.; Martínez, D.E.; Mohr, C.; Humbeck, K.; Guiamet, J.J. In vivo inhibition of cysteine proteases provides evidence for the involvement of 'senescence-associated vacuoles' in chloroplast protein degradation during dark-induced senescence of tobacco leaves. J. Exp. Bot. 2013, 64, 4967-4980. [CrossRef] [PubMed]

55. Kichey, T.; Heumez, E.; Pocholle, D.; Pageau, K.; Vanacker, H.; Dubois, F.; Le Gouis, J.; Hirel, B. Combined agronomic and physiological aspects of nitrogen management in wheat highlight a central role for glutamine synthetase. New Phytol. 2006, 169, 265-278. [CrossRef] [PubMed]

56. Simpson, R.J.; Dalling, M.J. Nitrogen redistribution during grain growth in wheat (Triticum aestivum L.): III. Enzymology and transport of amino acids from senescing flag leaves. Planta 1981, 151, 447-456. [CrossRef] [PubMed]

57. Goron, T.L.; Raizada, M.N. Biosensor-based spatial and developmental mapping of maize leaf glutamine at vein-level resolution in response to different nitrogen rates and uptake/assimilation durations. BMC Plant Biol. 2016, 16, 230. [CrossRef]

58. Wu, X.Y.; Hu, W.J.; Luo, H.; Xia, Y.; Zhao, Y.; Wang, L.D.; Zhang, L.M.; Luo, J.C.; Jing, H.C. Transcriptome profiling of developmental leaf senescence in sorghum (Sorghum bicolor). Plant Mol. Biol. 2016, 92, 555-580. [CrossRef]

59. Humbeck, K. Epigenetic and small RNA regulation of senescence. Plant Mol. Biol. 2013, 82, 529-537. [CrossRef]

60. Duan, Z.; Shen, C.; Li, Q.; Lü, G.; Ni, Y.; Yu, D.; Niu, J. Identification of a novel male sterile wheat mutant $d m s$ conferring dwarf status and multi-pistils. J. Integr. Agric. 2015, 14, 1706-1714. [CrossRef]

61. He, R.; Ni, Y.; Li, J.; Jiao, Z.; Zhu, X.; Jiang, Y.; Li, Q.; Niu, J. Quantitative changes in the transcription of phytohormone-related genes: Some transcription factors are major causes of the wheat mutant $d m c$ not tillering. Int. J. Mol. Sci. 2018, 19, 1324. [CrossRef] [PubMed]

62. Zhu, X.X.; Li, Q.Y.; Shen, C.C.; Duan, Z.B.; Yu, D.Y.; Niu, J.S.; Ni, Y.J.; Jiang, Y.M. Transcriptome analysis for abnormal spike development of the wheat mutant $d m s$. PLoS ONE 2016, 11, e0149287. [CrossRef] [PubMed]

63. Kim, D.; Pertea, G.; Trapnell, C.; Pimentel, H.; Kelley, R.; Salzberg, S.L. TopHat2: Accurate alignment of transcriptomes in the presence of insertions, deletions and gene fusions. Genome Biol. 2013, 14, R36. [CrossRef] [PubMed]

64. Florea, L.; Song, L.; Salzberg, S.L. Thousands of exon skipping events differentiate among splicing patterns in sixteen human tissues. F1000Research 2013, 2, 188. [CrossRef] [PubMed]

65. Wang, L.; Feng, Z.; Wang, X.; Wang, X.; Zhang, X. DEGseq: An R package for identifying differentially expressed genes from RNA-seq data. Bioinformatics 2010, 26, 136-138. [CrossRef] [PubMed]

66. Schulze, S.K.; Kanwar, R.; Gölzenleuchter, M.; Therneau, T.M.; Beutler, A.S. SERE: Single-parameter quality control and sample comparison for RNA-Seq. BMC Genom. 2012, 13, 524. [CrossRef] [PubMed] 
67. Fahlgren, N.; Howell, M.D.; Kasschau, K.D.; Chapman, E.J.; Sullivan, C.M.; Cumbie, J.S.; Givan, S.A.; Law, T.F.; Grant, S.R.; Dangl, J.L.; et al. High-throughput sequencing of Arabidopsis microRNAs: Evidence for frequent birth and death of MIRNA genes. PLoS ONE 2017, 2, e219. [CrossRef] [PubMed]

68. Anders, S.; Huber, W. Differential expression analysis for sequence count data. Genome Biol. 2010, 11, R106. [CrossRef] [PubMed]

69. Allen, E.; Xie, Z.; Gustafson, A.M.; Carrington, J.C. MicroRNA-directed phasing during trans-acting siRNA biogenesis in plants. Cell 2005, 121, 207-221. [CrossRef]

70. Geng, D.; Chen, P.; Shen, X.; Zhang, Y.; Li, X.; Jiang, L.; Xie, Y.; Niu, C.; Zhang, J.; Huang, X.; et al. MdMYB88 and MdMYB124 enhance drought tolerance by modulating root vessels and cell walls in apple. Plant Physiol. 2018, 178, 1296-1309. [CrossRef]

71. Phan, H.A.; Iacuone, S.; Li, S.F.; Parish, R.W. The MYB80 transcription factor is required for pollen development and the regulation of tapetal programmed cell death in Arabidopsis thaliana. Plant Cell 2011, 23, 2209-2224. [CrossRef] [PubMed]

72. Smith, P.K.; Krohn, R.I.; Hermanson, G.T.; Mallia, A.K.; Gartner, F.H.; Provenzano, M.D.; Fujimoto, E.K.; Goeke, N.M.; Olson, B.J.; Klenk, D.C. Measurement of protein using bicinchoninic acid. Anal. Biochem. 1985, 150, 76-85. [CrossRef]

73. Breuil, C.; Saddler, J.N. Comparison of the 3,5-dinitrosalicylic acid and Nelson-Somogyi methods of assaying for reducing sugars and determining cellulase activity. Enzym. Microb. Technol. 1985, 7, 327-332. [CrossRef]

74. Cataldo, D.A. Rapid colorimetric determination of nitrate in plant tissue by nitration of salicylic acid. Commun. Soil Sci. Plant Anal. 1975, 6, 71-80. [CrossRef]

75. Krom, M.D. Spectrophotometric determination of ammonia: A study of a modified berthelot reaction using salicylate and dichloroisocyanurate. Analyst 1980, 105, 305-316. [CrossRef]

76. Tiedemann, A.V. Evidence for a primary role of active oxygen species in induction of host cell death during infection of bean leaves with Botrytis cinerea. Physiol. Mol. Plant Pathol. 1997, 50, 151-166. [CrossRef]

77. Li, J.; Cheng, Z.; Yang, X.L.; Li, S.; Gu, M.; Wan, S.W.; Zhang, W.J.; Chen, J.K. Determination of lignin content in tiny Panax ginseng by UV spectrophotometry. J. Chin. Med. Mater. 2006, 29, 239-241.

78. Yu, X.; Wang, B.; Zhang, C.; Xu, W.; He, J.; Zhu, L.; Wang, S. Effect of root restriction on nitrogen levels and glutamine synthetase activity in 'Kyoho' grapevines. Sci. Hortic. 2012, 137, 156-163. [CrossRef]

79. Mohammadi, M.; Roohparvar, R.; Torabi, M. Induced chitinase activity in resistant wheat leaves inoculated with an incompatible race of Puccinia striiformis f. sp. tritici, the causal agent of yellow rust disease. Mycopathologia 2002, 154, 119-226. [CrossRef] 